\title{
Current developments on polyhydroxyalkanoates synthesis by using halophiles as a promising cell factory
}

Ruchira Mitra ${ }^{1,2}$, Tong $X u^{1}$, Hua Xiang ${ }^{1,3^{*}}$ and Jing $\operatorname{Han}^{1,3^{*}}$

\begin{abstract}
Plastic pollution is a severe threat to our environment which necessitates implementation of bioplastics to realize sustainable development for a green world. Polyhydroxyalkanoates (PHA) represent one of the potential candidates for these bioplastics. However, a major challenge faced by PHA is the high production cost which limits its commercial application. Halophiles are considered to be a promising cell factory for PHA synthesis due to its several unique characteristics including high salinity requirement preventing microbial contamination, high intracellular osmotic pressure allowing easy cell lysis for PHA recovery, and capability to utilize wide spectrum of low-cost substrates. Optimization of fermentation parameters has made it plausible to achieve large-scale production at low cost by using halophiles. Further deeper insights into halophiles have revealed the existence of diversified and even novel PHA synthetic pathways within different halophilic species that greatly affects PHA type. Thus, precise metabolic engineering of halophiles with the help of advanced tools and strategies have led to more efficient microbial cell factory for PHA production. This review is an endeavour to summarize the various research achievements in these areas which will help the readers to understand the current developments as well as the future efforts in PHA research.
\end{abstract}

Keywords: Polyhydroxyalkanoates, Halophiles, Production improvement, Cost reduction, Novel PHA biosynthesis, Metabolic engineering

\section{Background}

The petrochemical-derived plastics feature one of the most important components in our daily lives. However, with skyrocketing plastic production and usage, plastic pollution has become one of the most alarming and obvious threat to all forms of life [1]. Despite of its enormous societal benefits, plastics account for significant waste accumulation which mostly remains undegraded and recalcitrant for decades in our ecosystem [2]. A possible panacea to these problems may be the use of biodegradable and biosynthetic plastics as an alternative.

\footnotetext{
*Correspondence: xiangh@im.ac.cn; hanjing@im.ac.cn

1 State Key Laboratory of Microbial Resources, Institute of Microbiology, Chinese Academy of Sciences, Beijing 100101, People's Republic of China

Full list of author information is available at the end of the article
}

Polyhydroxyalkanoates (PHA) are linear polyesters synthesized by a variety of microorganisms, serving as an intracellular reservoir for energy and carbon supply [3, 4]. Owing to their combined properties of biodegradability, biocompatibility, and thermoplasticity, PHA has gained substantial importance as a promising candidate for bio-based plastics as well as biomaterials [5]. Interestingly, properties of PHA are highly tuneable and versatile as they vary depending on the type and amount of monomer constituents. Till now, over 150 different monomers have been incorporated into PHA chains under various fermentation conditions, yielding PHA with different characteristics [6]. PHA has tremendous market potential but the high production cost has limited its commercial applications [7]. Recently, halophiles are attracting 
considerable interest as a promising and cost-effective producer of PHA [8].

Halophiles represent a distinctive and diversified group of microorganisms that have the ability to survive in hypersaline habitats such as saline lakes, salt pans, and salt marshes. They are widely spread in all the three domains of life, Bacteria, Archaea, and Eukarya [9]. Based on their optimum salinity for growth, microorganisms requiring salts are classified as mild, moderate, and extreme halophiles. Mild halophiles grow at a salt concentration of $1-6 \%(\mathrm{w} / \mathrm{v})$ whereas moderate and extreme halophiles can grow at salt concentrations of $7-15 \%(\mathrm{w} / \mathrm{v})$ and higher than $15 \%(\mathrm{w} / \mathrm{v})$, respectively [10]. As a survival strategy, halophiles maintain a high osmotic pressure to adapt to the surrounding hypersaline environment by accumulating either high concentrations of $\mathrm{K}^{+}$salts or soluble organic solutes (known as compatible solutes) [11]. Some compatible solutes have captured the interest of researchers due to their high value-added property. For instance, ectoine has high commercial importance as an osmostress protectant in cosmetic industry [12]. Additionally, hydrolytic enzymes including amylase, cellulase, protease, and xylanase, secreted by halophiles are also very useful for industrial processes under hypersaline conditions [13]. Furthermore, halophiles are a potent source of biosurfactant, bioemulsifiers, and various other chemicals including aminophenoxazinones, carotenoids, and bacteriorhodopsin [8, 14]. Especially, most halophiles have the inherent ability to accumulate PHA intracellularly.

The adaptation of halophiles to extreme conditions has bestowed them with unique potentials and advantages for PHA production. The foremost advantage is that the high salinity requirement reduces the chances of microbial contamination to a great extent [15]. PHA recovery cost is further reduced as cells can be easily lysed in normal water due to the high intracellular osmotic pressure [16]. Moreover, compared to the non-halophilic microbes, halophiles have the ability to produce PHA by utilizing various inexpensive raw materials, thus reducing the fermentation cost [17]. Thus, they are considered as a promising candidate for PHA production. The company named Bluepha in China is producing polyhydroxybutyrate (PHB) and poly(3-hydroxybutyrate-co-3-hydroxyvalerate) (PHBV) using a Halomonas species as microbial cell factory. However, there are still some challenges when using halophiles for large-scale PHA production. For example, treatment of the saline fermentation effluent is difficult [18]. The high salt concentration of medium corrodes fermentation equipment. Additionally, lack of genetic engineering tools and less well-defined systems might be also great challenges for large-scale production of PHA using halophiles. With growing research, strategies have been developed to overcome these issues. Saline wastewater can be treated by marine bacteria [19]. Salt-resistant fermentation equipments made of plastics, ceramics or carbon steel have been used to culture halophiles [8]. Especially, development of genetically engineered halophilic strains is likely to enhance the efficiency of large-scale PHA production by halophiles.

At present, there are many reviews already published on PHA synthesis, and its related challenges and future applications [15, 20-22]. However, most of these reviews focus on non-halophiles. An integrated review mainly presenting the current scenario of PHA synthesis by both the haloarchaea and halophilic bacteria is relatively less. Research on PHA synthesis by halophiles is accelerating and thus, it is urgent to present an updated and in-depth review on this field. In this review, the progresses on PHA synthesis by haloarchaea and halophilic bacteria have been outlined (Fig. 1). The first two parts of the review include significance of halophiles as PHA producer and the various fermentation strategies adopted to realize low cost halophile-mediated PHA production. The third part presents important insights on the PHA metabolism and its regulation in halophiles. Finally, the fourth part of the review deals with the application of metabolic engineering techniques for enhancement of PHA production and synthesis of novel PHA.

\section{Halophiles as a promising platform for PHA production}

Among halophiles, the haloarchaeon Haloferax mediterranei and the Halomonas species from bacterial domain have been extensively studied for efficient PHA production. Up to now, $H f x$. mediterranei has been reported to synthesize PHBV and poly(3-hydroxybutyrate-co3-hydroxyvalerate-co-4-hydroxybutyrate) (PHBV4HB) [23]; Halomonas species can accumulate PHB, PHBV, and poly(3-hydroxybutyrate-co-4-hydroxybutyrate) (P3HB4HB) [24-26] (Fig. 2). More and more promising candidates from different genera have already marked their prominence in this field. Thus, the following section attempts to introduce the wide range of PHA-producing halophiles to the readers.

\section{Haloarchaea as PHA producers}

Ever since Kirk and Ginzburg reported the presence of PHB in Halobacterium sp. isolated from Dead Sea, (presently known as Haloarcula marismortui), more and more haloarchaeal species with PHA-accumulating ability have been identified (Table 1) [27]. In 1986, Fernandez-Castillo et al. detected the presence of PHB in four more haloarchaeal species which are now known as $H f x$. mediterranei, Haloferax volcanii, Haloferax gibbonsii, and Haloarcula hispanica [28]. In the period from 1990 


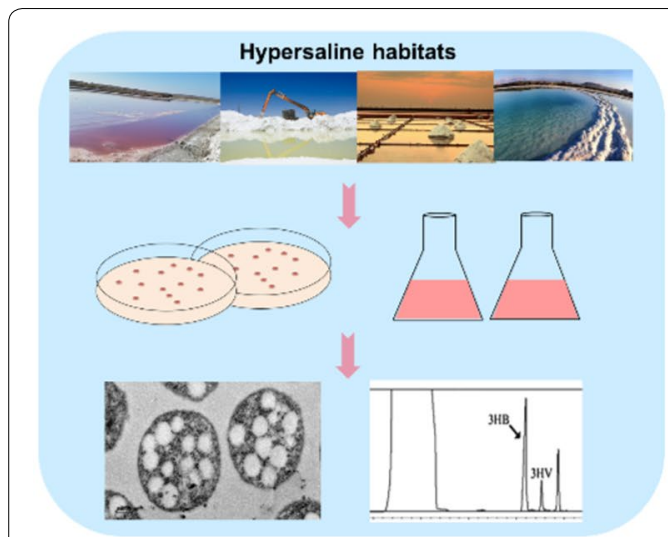

Mining PHA-producing halophiles

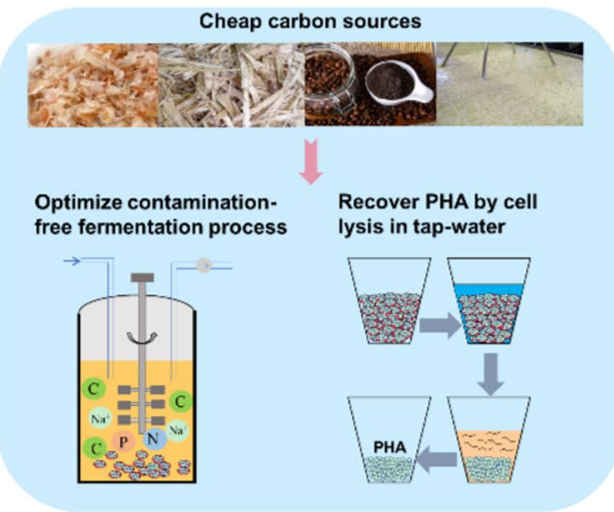

Low-cost fermentation strategies

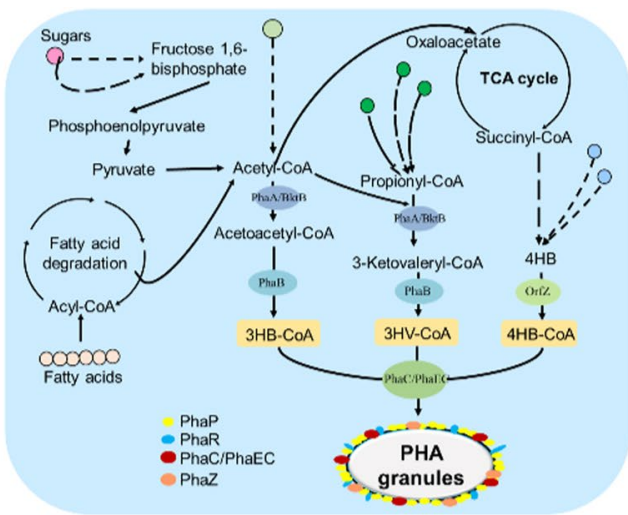

Diversified and novel PHA metabolisms

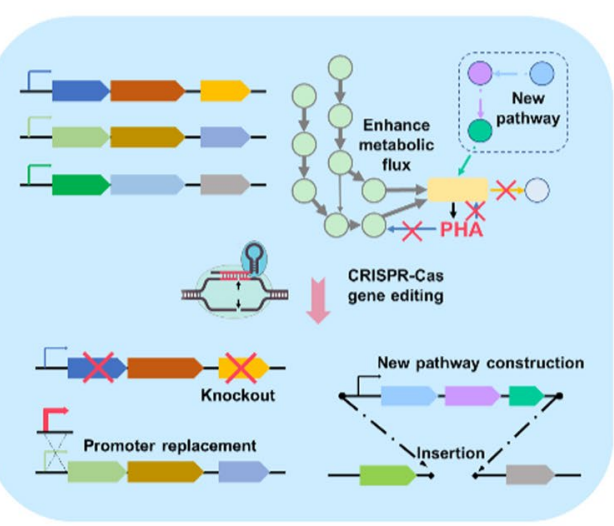

Fine tuning for efficient or novel PHA synthesis

Fig. 1 Summary of the PHA research achievements in Haloarchaea and Halophilic bacteria. Halophiles with strong PHA-accumulation ability are mined from various hypersaline habitats. PHA production cost is closely related with substrate usage, fermentation process, and PHA recovery. Halophiles are able to utilize a wide-range of low-cost substrates. PHA recovery from halophiles can be easily done by cell lysis using tap-water. The physicochemical parameters and fermentation modes have been optimized to enhance PHA production in halophiles. With the aim of genome sequencing technology and genetic manipulation tools, various PHA related genes, enzymes and pathways have been identified. With the help of advanced metabolic engineering tools and strategies, more efficient microbial cell factory has been developed for PHA production using halophiles

to 2000, PHA accumulation was detected in two more Haloarcula species, namely, Haloarcula vallismortis [29, 30] and Haloarcula japonica [30]. Following this, Halopiger aswanensi was found to accumulate PHB accounting about $53 \%$ of its cell dry weight (CDW), when n-butyric acid and sodium acetate were used as carbon sources [31, 32]. The presence of PHA granules was further observed in two Haloquadratum walsbyi species [33]. By 2010, PHA accumulation was reported in several other haloarchaeal species including, Halostagnicola sp., Haloterrigena sp., Halobiforma sp., Haloarcula sp., Halobacterium sp., Halococcus sp., Halorubrum sp., Natrinema sp. and haloalkaliphiles including Natronobacterium sp. and Natronococcus sp. [34-37]. In 2017, it was reported that Halorubrum lacusprofundi, the third most abundant species in the Deep Lake community of Antarctica, produced PHA-like granules at low temperature [38]. To date, haloarchaeal species belonging to almost 17 genera have been reported to exhibit PHA-accumulating ability (Table 1).

Among all the haloarchaeal strains, $H f x$ mediterranei is so far the most preferable PHA producer. It has several advantages such as high growth rate, metabolic versatility, genetic stability, and an efficient transformation system [14]. Many reports have also shown that $H f x$. mediterranei has the ability to utilize various industrial and household waste products as carbon sources for synthesizing PHA with considerable amount of productivity. Moreover, detailed investigations have revealed that the PHA produced by the strain is a copolymer of 3-hydroxybutyrate (3HB) and 3-hydroxyvalerate (3HV) from unrelated carbon sources [39]. PHBV is a commercially more 
a PHA types synthesized by Haloferax mediterranei<smiles>CCC(CC=O)OC(C)(C)C(=O)CC(C)OC</smiles>

PHBV<smiles>CCC(CC(=O)C(C)(C)OCCCC(C)(C)C)OC(C)(C)C(=O)CC(C)OC(C)(C)C</smiles>

PHBV4HB

\section{b PHA types synthesized by Halomonas species}<smiles>CCCCC(C)CC(C)COC</smiles>

PHB<smiles>CCC(CC=O)OC(C)(C)C(=O)CC(C)OC(C)(C)C</smiles>

PHBV<smiles>CCC(=O)C(C)CC(=O)CCOC(C)(C)CCCCOC(C)C</smiles>

\section{P3HB4HB}

Fig. 2 The PHA types synthesized by Haloferax mediterranei and Halomonas species. Hfx. mediterranei can synthesize PHBV and PHBV4HB. Halomonas species are able to accumulate PHB, PHBV, and P3HB4HB

efficient and favourable polymer than PHB [4]. Most organisms require $3 \mathrm{HV}$ precursor for PHBV synthesis whereas $H f x$. mediterranei can efficiently synthesize PHBV without any precursor, thus greatly reducing the production cost [40]. Moreover, it was clearly evident that the cost of PHA production using Hfx. mediterranei was much lower than other bacteria including Alcaligenes eutrophus, Pseudomonas hydrogenovora, and Hydrogenophaga pseudoflava [40]. Thus, Hfx. mediterranei is considered as one of the most promising microbial cell factories for large-scale PHBV production. Other strains including Har. hispanica, Halogeometricum borinquense, and Natrinema species were also found to accumulate PHBV only by utilizing unrelated carbon sources [4144]. For example, Natrinema ajinwuensis accumulated PHBV containing $13.93 \mathrm{~mol} \% 3 \mathrm{HV}$ by using glucose as the sole carbon source [45]. Halogranum amylolyticum could also efficiently accumulate PHBV with $20.1 \mathrm{~mol} \%$ $3 \mathrm{HV}$ from glucose [46]. However, unlike $H f x$. mediterranei, these haloarchaea have drawbacks as a platform to be further optimized for PHA production, such as low $3 \mathrm{HV}$ content in PHBV, slow growth rate, requirement for 
Table 1 Haloarchaeal genera with PHA-accumulating ability

\begin{tabular}{|c|c|c|}
\hline Genus & Species & References \\
\hline \multirow[t]{6}{*}{ Haloarcula } & Haloarcula marismortui & [27] \\
\hline & Haloarcula hispanica & {$[28]$} \\
\hline & Haloarcula vallismortis & {$[29,30]$} \\
\hline & Haloarcula japonica & {$[30]$} \\
\hline & Haloarcula amylolytica & {$[35]$} \\
\hline & Haloarcula argentinensis & [35] \\
\hline \multirow[t]{3}{*}{ Haloferax } & Haloferax mediterranei & [28] \\
\hline & Haloferax volcanii & [28] \\
\hline & Haloferax gibbonsii & {$[28]$} \\
\hline Halopiger & Halopiger aswanensi & {$[31,32]$} \\
\hline Haloquadratum & Haloquadratum walsbyi & [33] \\
\hline \multirow[t]{3}{*}{ Halobacterium } & Halobacterium noricense & {$[36]$} \\
\hline & Halobacterium cutirubrum & {$[35]$} \\
\hline & Halobacterium halobium & [35] \\
\hline Halostagnicola & Halostagnicola larsenii & {$[35]$} \\
\hline \multirow[t]{2}{*}{ Haloterrigena } & Haloterrigena hispanica & {$[37]$} \\
\hline & Haloterrigena turkmenica & [35] \\
\hline \multirow[t]{2}{*}{ Halobiforma } & Halobiforma nitratireducens & [35] \\
\hline & Halobiforma haloterrestris & [34] \\
\hline \multirow[t]{6}{*}{ Halococcus } & Halococcus morrhuae & {$[35,36]$} \\
\hline & Halococcus saccharolyticus & {$[36]$} \\
\hline & Halococcus salifodinae & {$[36]$} \\
\hline & Halococcus dombrowskii & {$[36]$} \\
\hline & Halococcus hamelinensis & {$[36]$} \\
\hline & Halococcus qingdaonensis & {$[36]$} \\
\hline \multirow[t]{5}{*}{ Halorubrum } & Halorubrum coriense & {$[36]$} \\
\hline & Halorubrum chaoviator & {$[36]$} \\
\hline & Halorubrum litoreum & {$[35]$} \\
\hline & Halorubrum trapanicum & {$[35]$} \\
\hline & Halorubrum lacusprofundi & [38] \\
\hline Halalkalicoccus & Halalkalicoccus tibetensis & {$[35]$} \\
\hline Halogeometricum & Halogeometricum borinquense & {$[42]$} \\
\hline Halogranum & Halogranum amylolyticum & {$[46]$} \\
\hline \multirow[t]{4}{*}{ Natrinema } & Natrinema altunense & [35] \\
\hline & Natrinema pallidum & {$[35]$} \\
\hline & Natrinema pellirubrum & {$[35]$} \\
\hline & Natrinema ajinwuensis & {$[45]$} \\
\hline Natronobacterium & Natronobacterium gregoryi & {$[35,36]$} \\
\hline Natronorubrum & Natronorubrum tibetense & {$[35]$} \\
\hline Natronococcus & Natronococcus occultus & {$[36]$} \\
\hline
\end{tabular}

too high salinity, or absence of tractable genetic transformation system. Nevertheless, these reports indicate that with passing years more and more haloarchaea are being identified with PHBV synthesis capability.
Table 2 Halophilic bacteria with PHA-accumulating ability

\begin{tabular}{lll}
\hline Genus & Species & References \\
\hline Halomonas & Halomonas boliviensis & {$[47-49]$} \\
& Halomonas sp. KM-1 & {$[50,144]$} \\
& Halomonas bluephagenesis TD01 & {$[51]$} \\
& Halomonas nitroreducens & {$[145]$} \\
& Halomonas sp. O-1 & {$[101]$} \\
& Halomonas elongata & {$[101]$} \\
& Halomonas halophila & {$[73]$} \\
& Halomonas marina & {$[53]$} \\
& Halomonas maura & {$[146]$} \\
& Halomonas ventosae & {$[147]$} \\
& Halomonas halodenitrificans & {$[148]$} \\
& Halomonas halodeneurihalina & {$[148]$} \\
Halorio & Halomonas salina & {$[148]$} \\
Yangia & Halomonas sp. SF2003 & {$[102]$} \\
& Halomonas profundus & {$[54]$} \\
& Halomonas hydrothermalis & {$[56]$} \\
& Vibrio proteolyticus & {$[77]$} \\
& Yangia sp. ND199 & {$[55]$} \\
& Yangia sp. CCB-MM3 & {$[57]$} \\
& Paracoccus sp. LL1 & {$[107]$} \\
& & {$[75]$} \\
& &
\end{tabular}

Halophilic bacteria as PHA producers

Within the bacterial domain, most PHA producers requiring salts belong to the family Halomonadaceae. Of almost 12 genera (as of May 2017) of Halomonadaceae, the genus Halomonas is known to accumulate short-chain-length PHA (Table 2). Most Halomonas sp. have lower $\mathrm{NaCl}$ requirement (3-15\%) for optimal growth compared to haloarchaea but the concentration is sufficient enough to prevent microbial contamination. Halomonas boliviensis, an alkali tolerant and moderately halophilic bacterium, has the ability to efficiently synthesize PHB at an average content of $50 \%$ (wt) by utilizing glucose, sucrose, maltose, xylose as well as wheat bran [47-49]. In 2010, an alkaliphilic halophile, Halomonas sp. KM-1 was reported to produce PHB using waste glycerol as sole carbon source [50]. Another halophilic strain Halomonas bluephagenesis TD01 was cultured in a twostage unsterile, open and continuous fermentation process yielding PHB up to $65-70 \%$ (wt) using glucose [51]. More and more Halomonas species have been found to synthesize PHB by using glucose or other cheap carbon sources (Table 2).

However, unlike $H f x$. mediterranei, most halophilic bacteria require $3 \mathrm{HV}$ precursor to produce PHBV. $H$. bluephagenesis TD01 produces PHBV when propionic acid or valeric acid is provided additionally with glucose [52]. Halomonas marina produces PHBV with $12.8 \mathrm{~mol} \%$ 
$3 \mathrm{HV}$ in glucose medium supplemented with valeric acid [53]. Similarly, Halomonas profundus produces PHBV with different molar fractions of $3 \mathrm{HV}$ in the presence of valeric acid and propionic acid [54]. Very recently, a PHB-producing halophile named Vibrio proteolyticus was isolated from Korean seas and it was additionally found to produce PHBV containing $15.8 \mathrm{~mol} \% 3 \mathrm{HV}$ when propionic acid was added as a co-substrate of fructose [55]. As an exception, Halomonas campisalis, a moderately haloalkalitolerant bacterium, was reported to produce PHBV with $3.6 \mathrm{~mol} \% 3 \mathrm{HV}$ from maltose [56]. Although the $3 \mathrm{HV}$ content in this copolymer was quite low, this was a significant finding as it was the first report on PHBV synthesis by a halophilic bacterium using unrelated carbon source. In 2015, Yangia sp. ND199, belonging to the Rhodobacteraceae family, was reported to accumulate PHBV with a range of 1-7 mol\% 3HV from unrelated carbon source including glucose, maltose, sucrose and glycerol [57]. Taken together, although $H$. bluephagenesis TD01 synthesize only PHB from unrelated carbon source, it has emerged as a strong candidate for industrial PHA production with the establishment of tractable genetic system, the completion of genome sequencing, and the wide application of metabolic engineering.

\section{Fermentation strategies for reducing the cost of halophile-mediated PHA production}

The large-scale production of PHA has high benefits in fermentation industry. A major drawback of PHA production is its economical uncompetitiveness with petroleum-based plastics. However, it has been possible to employ non-halophiles including Alcaligenes latus, Bhurkolderia sp., Ralstonia eutropha, and recombinant Escherichia coli for industrial PHA production after numerous attempts of cost reduction [58]. It is obvious that commercialization of halophiles will have added benefits of cost-effective and contamination-free fermentation compared to these non-halophiles. Three important factors contribute to the cost of PHA production-substrate usage, fermentation process, and PHA recovery. As PHA recovery from halophiles can be easily done by cell lysis using tap-water, rigorous efforts have been devoted to the first two factors. PHA synthesized by various halophiles using cheap carbon sources are summarized in Tables 3 and 4.

\section{Low-cost substrate usage by haloarchaea}

Besides the common challenges faced by halophiles, the major bottleneck faced by haloarchaea species, such as $H f x$. mediterranei, is the low PHA productivity resulted from slow growth rate, and failing to achieve high celldensity cultivation and continuous fermentation. Due to this problem, $H f x$. mediterranei has not been used to produce PHA in a large scale despite the fact that it does not require additional $3 \mathrm{HV}$ precursor. A possible strategy to overcome these challenges is usage of low-cost substrate which can compensate the high production cost resulting from low productivity. The raw materials account for almost $40-48 \%$ of the PHA production cost [59]. Replacement of the pure and expensive raw materials for PHA production is a big challenge for the researchers.

$H f x$. mediterranei have the ability to utilize cheap carbon source and even agro-industrial wastes to synthesize PHA (Table 3). Utilization of waste by-products not only helps in waste management but also contributes to reducing PHA production cost. For instance, ethanol production from sugarcane or sugar beet generates considerable amounts of vinasse, which if indiscriminately disposed can be a potential risk to the eco-system [60]. Interestingly, $H f x$. mediterranei can utilize pre-treated vinasse and accumulate $70 \%$ (wt) PHBV [61]. Olive mill wastewater, a highly problematic waste generated from olive oil industry, serves as the sole carbon source for $H f x$. mediterranei, yielding 43\% (wt) of PHBV [62]. Chitin is one of the most abundant natural polysaccharides. Seafood industries generate enormous amounts of chitin waste which are mostly recalcitrant in nature. Hfx. mediterranei encodes the enzymes of chitin catabolism and can effectively utilize chitin as a sole carbon source to produce PHBV at a concentration of $1 \mathrm{~g} / \mathrm{L}$ [63]. Cheese whey, the major by-product of dairy industry is an enriched source of milk nutrients. Since, $H f x$. mediterranei was unable to utilize lactose, enzymatically hydrolysed cheese whey was used as the sole carbon source, and 72.8\% (wt) of PHBV was produced [23]. Because enzymatic hydrolysis can incur additional cost, chemical hydrolysis using hydrochloric acid was further employed to hydrolyse whey into glucose and galactose [64]. Micronutrients were additionally supplemented to favour galactose utilization for PHBV synthesis after glucose was consumed, which led to production of $53 \%$ (wt) PHBV in Hfx. mediterranei. Stillage emanating from rice-based ethanol manufacturing unit is an attractive low-cost substrate for PHA production. Hfx. mediterranei utilized raw stillage and produced 71\% (wt) PHBV [65]. When stillage was used to produce $\mathrm{PHBV}$ in a plug-flow reactor configuration of the activated sludge process, $H f x$. mediterranei was able to accumulate $63 \%$ (wt) PHBV while $99.3 \%$ of the medium salt was recovered for re-use [66]. Additionally, the cost for 1890 tons of PHBV was estimated to be as low as US\$ $2.05 / \mathrm{kg}$. This was almost comparable with the production cost of 2000 tons PHB by Cupriavidus necator (US\$2.58/ $\mathrm{kg}$ ) [67]. Thus, this study holds high significance for constructing pilot-scale plant for PHBV production using $H f x$. mediterranei and also forms a basis for integration 
Table 3 PHA production by haloarchaea using various substrates

\begin{tabular}{|c|c|c|c|c|c|}
\hline Microorganism & Carbon source & PHA type & PHA production & $\begin{array}{l}\text { Fermentation operation } \\
\text { mode }\end{array}$ & References \\
\hline Har. hispanica & Glucose & $\mathrm{P}(3 \mathrm{HB}-\mathrm{co}-3.18 \mathrm{~mol} \% 3 \mathrm{HV})$ & Content of $12.26 \%$ (wt) & Shake flasks & {$[105]$} \\
\hline Har. marismortui & $100 \%$ pre-treated vinasse & PHB & $\begin{array}{l}\text { Content of } 30 \% \text { (wt); yield } \\
\text { of } 0.77 \mathrm{~g} / \mathrm{g} \text {; productivity } \\
\text { of } 0.02 \mathrm{~g} / \mathrm{L} / \mathrm{h}\end{array}$ & Shake flasks & {$[69]$} \\
\hline Hfx. mediterranei & Glucose & $\mathrm{P}(3 \mathrm{HB}-\mathrm{co}-12.4 \mathrm{~mol} \% 3 \mathrm{HV})$ & Content of $16.4 \%$ (wt) & Shake flasks & {$[35]$} \\
\hline Hfx. mediterranei & Extruded starch & P(3HB-co-10.4 mol\% 3HV) & Content of $50.8 \%$ (wt) & Fed-batch & {$[85]$} \\
\hline Hfx. mediterranei & $25 \%$ pre-treated vinasse & $\mathrm{P}(3 \mathrm{HB}-\mathrm{co}-12.36 \mathrm{~mol} \% 3 \mathrm{HV})$ & $\begin{array}{l}\text { Content of } 70 \% \text { (wt); yield } \\
\text { of } 0.87 \mathrm{~g} / \mathrm{g} \text {; productivity } \\
\text { of } 0.21 \mathrm{~g} / \mathrm{L} / \mathrm{h}\end{array}$ & Shake flasks & {$[61]$} \\
\hline Hfx. mediterranei & $50 \%$ pre-treated vinasse & P(3HB-co-14.09 mol\% 3HV) & $\begin{array}{l}\text { Content of } 66 \% \text { (wt); yield } \\
\text { of } 0.52 \mathrm{~g} / \mathrm{g} \text {; productivity } \\
\text { of } 0.18 \mathrm{~g} / \mathrm{L} / \mathrm{h}\end{array}$ & Shake flasks & {$[61]$} \\
\hline Hfx. mediterranei & Olive mill wastewater & $\mathrm{P}(3 \mathrm{HB}-\mathrm{co}-6.5 \mathrm{~mol} \% 3 \mathrm{HV})$ & Content of $43 \%$ (wt) & Shake flasks & {$[62]$} \\
\hline Hfx. mediterranei & $\begin{array}{l}\text { Enzymatic hydrolysate of } \\
\text { cheese whey }\end{array}$ & $\mathrm{P}(3 \mathrm{HB}-\mathrm{co}-6 \mathrm{~mol} \%$ 3HV) & $\begin{array}{l}\text { Content of } 72.8 \% \text { (wt), yield } \\
\text { of } 0.29 \mathrm{~g} / \mathrm{g} \text {; productivity } \\
\text { of } 0.09 \mathrm{~g} / \mathrm{L} / \mathrm{h}\end{array}$ & 42-L bioreactor & {$[23]$} \\
\hline Hfx. mediterranei & $\begin{array}{l}\text { Chemical hydrolysate of } \\
\text { cheese whey }\end{array}$ & $\mathrm{P}(3 \mathrm{HB}-\mathrm{co}-1.5 \mathrm{~mol} \% 3 \mathrm{HV})$ & $\begin{array}{l}\text { Content of } 53 \% \text { (wt); yield } \\
\text { of } 0.78 \mathrm{~g} / \mathrm{g} \text {; productivity } \\
\text { of } 4.04 \mathrm{~g} / \mathrm{L} / \text { day }\end{array}$ & 2-L bioreactor & {$[64]$} \\
\hline Hfx. mediterranei & Waste stillage & $\mathrm{P}(3 \mathrm{HB}-\mathrm{co}-15.4 \mathrm{~mol} \% 3 \mathrm{HV})$ & $\begin{array}{l}\text { Content of } 71 \% \text { (wt); yield } \\
\text { of } 0.35 \mathrm{~g} / \mathrm{g} \text {; productivity } \\
\text { of } 0.17 \mathrm{~g} / \mathrm{L} / \mathrm{h}\end{array}$ & Shake flasks & {$[65]$} \\
\hline Hfx. mediterranei & Waste stillage & $\mathrm{P}(3 \mathrm{HB}-\mathrm{co}-17.9 \mathrm{~mol} \% 3 \mathrm{HV})$ & $\begin{array}{l}\text { Content of } 63 \%(w t) \text {; yield } \\
\text { of } 0.27 \mathrm{~g} / \mathrm{g} \text {; productivity } \\
\text { of } 0.14 \mathrm{~g} / \mathrm{L} / \mathrm{h}\end{array}$ & Plug-flow reactor & {$[66]$} \\
\hline Hfx. mediterranei & Crude glycerol & $\mathrm{P}(3 \mathrm{HB}-\mathrm{co}-10 \mathrm{~mol} \% 3 \mathrm{HV})$ & $\begin{array}{l}\text { Content of } 76 \%(w t) \text {; yield } \\
\text { of } 0.19 \mathrm{~g} / \mathrm{g} ; \text { productivity } \\
\text { of } 0.12 \mathrm{~g} / \mathrm{L} / \mathrm{h}\end{array}$ & 10-L bioreactor & {$[68]$} \\
\hline Hfx. mediterranei & Ulva sp. hydrolysate & $\mathrm{P}(3 \mathrm{HB}-\mathrm{co}-8 \mathrm{~mol} \% 3 \mathrm{HV})$ & $\begin{array}{l}\text { Content of } 55 \%(w t) ; \text { pro- } \\
\text { ductivity of } 0.035 \mathrm{~g} / \mathrm{L} / \mathrm{h}\end{array}$ & Duran bottle & {$[71]$} \\
\hline Hfx. mediterranei & $\begin{array}{c}\text { Whey sugars, sodium valer- } \\
\text { ate and } \gamma \text {-butyrolactone }\end{array}$ & $\begin{array}{l}\mathrm{P}(3 \mathrm{HB}-\mathrm{co}-21.8 \mathrm{~mol} \% 3 \mathrm{HV}- \\
\quad \text { co-5.1 mo\% 4HB })\end{array}$ & $\begin{array}{l}\text { Content of } 87.5 \% \text { (wt); yield } \\
\text { of } 0.20 \mathrm{~g} / \mathrm{g} \text {; productivity } \\
\text { of } 0.14 \mathrm{~g} / \mathrm{L} / \mathrm{h}\end{array}$ & 10-L bioreactor & {$[23]$} \\
\hline Hfx. mediterranei & $\begin{array}{l}\text { Crude glycerol phase and } \\
\text { y-butyrolactone }\end{array}$ & $\begin{array}{l}\mathrm{P}(3 \mathrm{HB}-\mathrm{co}-10.0 \mathrm{~mol} \% 3 \mathrm{HV}- \\
\quad \text { co-5.0 mol\% 4HB })\end{array}$ & $\begin{array}{l}\text { Content of } 68.5 \% \text { (wt); yield } \\
\text { of } 0.16 \mathrm{~g} / \mathrm{g} \text {; productivity } \\
\text { of } 0.10 \mathrm{~g} / \mathrm{L} / \mathrm{h}\end{array}$ & 10-L bioreactor & {$[68]$} \\
\hline Hgn. amylolyticum & Glucose & $\mathrm{P}(3 \mathrm{HB}-\mathrm{co}-20.1 \mathrm{~mol} \% 3 \mathrm{HV})$ & Content of $26.1 \%$ (wt) & Shake flasks & {$[46]$} \\
\hline Hgn. amylolyticum & Starch & $\mathrm{P}(3 \mathrm{HB}-\mathrm{co}-18.7 \mathrm{~mol} \% 3 \mathrm{HV})$ & Content of $16.2 \%$ (wt) & Shake flasks & {$[46]$} \\
\hline Hgn. amylolyticum & Glycerol & $\mathrm{P}(3 \mathrm{HB}-\mathrm{co}-19.6 \mathrm{~mol} \% 3 \mathrm{HV})$ & Content of $7.2 \%$ (wt) & Shake flasks & {$[46]$} \\
\hline Hgm. borinquense & $\begin{array}{l}\text { Sugarcane bagasse hydro- } \\
\text { lysate }\end{array}$ & P(3HB-co-13.29 mol\% 3HV) & $\begin{array}{l}\text { Content of } 45.7 \% \text { (wt); yield } \\
\text { of } 0.253 \mathrm{~g} / \mathrm{g} \text {; productivity } \\
\text { of } 0.0113 \mathrm{~g} / \mathrm{L} / \mathrm{h}\end{array}$ & Shake flasks & {$[43]$} \\
\hline Nnm. ajinwuensis & Glucose & $\mathrm{P}(3 \mathrm{HB}-\mathrm{co}-13.93$ mol\% 3HV) & $\begin{array}{l}\text { Content of } 61.02 \%(\mathrm{wt}) ; \\
\text { productivity of } 0.21 \mathrm{~g} / \mathrm{L} / \mathrm{h}\end{array}$ & Repeated shake flasks & {$[45]$} \\
\hline
\end{tabular}

of PHA production with ethanol manufacturing unit to minimize the overall cost. Crude glycerol is the waste by-product of biodiesel production. Interestingly, $H f x$. mediterranei could utilize crude glycerol to give a PHBV concentration $(16.2 \mathrm{~g} / \mathrm{L})$ similar to that produced from pure glycerol $(13.4 \mathrm{~g} / \mathrm{L})$ [68]. Thus, utilization of crude glycerol opens up a possibility to integrate PHA production with the existing biodiesel production. This will significantly save the operational and transportation cost.
Other haloarchaeon including Har. marismortui and Hgm. borinquense strain E3 also have the ability to use low-cost substrates. Har. marismortui can utilize pretreated vinasse to accumulate 30\% (wt) PHB [69]. Sugarcane bagasse is a major lignocellulosic fibrous residue of sugarcane industry. Hgm. borinquense strain E3 showed 45.7\% (wt) accumulation of PHBV when hydrolysates of sugarcane bagasse were utilized as a feedstock for PHA synthesis [43]. 
Table 4 PHA production by halophilic bacteria using various substrates

\begin{tabular}{|c|c|c|c|c|c|}
\hline Microorganism & Carbon source & PHA type & $\begin{array}{l}\text { PHA } \\
\text { content (\% } \\
\text { CDW) }\end{array}$ & Fermentation operation mode & References \\
\hline H. halphila & Glucose & $\mathrm{PHB}$ & 81.5 & Shake flasks & [73] \\
\hline H. halphila & Cellobiose & $\mathrm{PHB}$ & 90.8 & Shake flasks & [73] \\
\hline H. halphila & Spent coffee grounds & PHB & 61.95 & Shake flasks & [73] \\
\hline H. halphila & Molasses & PHB & 64.06 & Shake flasks & [73] \\
\hline H. halphila & Cheese whey hydrolysate & PHB & 38.32 & Shake flasks & [73] \\
\hline H. halphila & Sawdust hydrolysates & $\mathrm{PHB}$ & 46.85 & Shake flasks & [73] \\
\hline H. halphila & Diluted corn stover hydrolysate & $\mathrm{PHB}$ & 38.67 & Shake flasks & [73] \\
\hline H. boliviensis & Maltose & $\mathrm{PHB}$ & 58.8 & Shake flasks & {$[48]$} \\
\hline H. boliviensis & Starch hydrolysate & $\mathrm{PHB}$ & $35-49$ & 2-L fermentor & [48] \\
\hline H. boliviensis & Butyric acid and sodium acetate & $\mathrm{PHB}$ & 54 & Shake flasks & [47] \\
\hline H. boliviensis & Butyric acid and sodium acetate & PHB & 88 & 2-L fermentor & [47] \\
\hline H. boliviensis & Glucose or sucrose & PHB & $\sim 55$ & 2-L fermentor & [47] \\
\hline H. boliviensis & $\begin{array}{l}\text { Wheat bran and digested potato } \\
\text { waste }\end{array}$ & $\mathrm{PHB}$ & 43 & 2-L fermentor & [49] \\
\hline H. boliviensis & Volatile fatty acid (VFA) & $\mathrm{P}(3 \mathrm{HB}-\mathrm{co}-8.5 \mathrm{~mol} \% 3 \mathrm{HV})$ & 70 & 2-L bioreactor & [74] \\
\hline Halomonas sp. KM-1 & $3 \%$ Waste glycerol & $\mathrm{PHB}$ & 39 & Shake flasks & {$[50]$} \\
\hline H. marina & Glucose & $\mathrm{PHB}$ & $>59$ & Shake-flasks & [53] \\
\hline H. marina & Glucose and $0.1 \%(\mathrm{w} / \mathrm{v})$ valerate & $\mathrm{P}(3 \mathrm{HB}-\mathrm{co}-12.8 \mathrm{~mol} \% 3 \mathrm{HV})$ & 80 & Shake-flasks & [53] \\
\hline V. proteolyticus & Fructose & $\mathrm{PHB}$ & 54.7 & Shake flasks & [55] \\
\hline V. proteolyticus & Fructose and $0.3 \%$ propionic acid & $\mathrm{P}(3 \mathrm{HB}-\mathrm{co}-15.8 \mathrm{~mol} \%$ 3HV) & $\approx 30$ & Shake flasks & [55] \\
\hline H. hydrothermalis & Jatropha biodiesel byproduct & $\mathrm{PHB}$ & 75 & Shake flasks & {$[77]$} \\
\hline H. hydrothermalis & $\begin{array}{l}\text { Jatropha biodiesel byproduct and } \\
\text { 0.35\% SDCLA }\end{array}$ & P(3HB-co-81 mol\% 3HV) & 73.3 & Shake flasks & [78] \\
\hline H. campisalis & Maltose & $\mathrm{P}(3 \mathrm{HB}-\mathrm{co}-3.6 \mathrm{~mol} \% 3 \mathrm{HV})$ & $45-81$ & Shake flasks & {$[56]$} \\
\hline Paracoccus sp. LL1 & Glucose & $\mathrm{PHB}$ & 62 & Shake flasks & {$[75]$} \\
\hline Paracoccus sp. LL1 & Xylose & PHB & 59 & Shake flasks & {$[75]$} \\
\hline Paracoccus sp. LL1 & Cellobiose & $\mathrm{PHB}$ & 59 & Shake flasks & {$[75]$} \\
\hline Paracoccus sp. LL1 & Corn stover hydrolysate & PHB & 72.4 & 5-L fermentor & {$[75]$} \\
\hline Yangia sp. ND199 & Glycerol & $\mathrm{P}(3 \mathrm{HB}-\mathrm{co}-2.9 \mathrm{~mol} \% 3 \mathrm{HV})$ & 52.8 & Shake flasks & [57] \\
\hline H. bluephagenesis TD01 & Glucose & $\mathrm{PHB}$ & $65-70$ & Open fed-batch and continuous & {$[51]$} \\
\hline H. campaniensis & $\begin{array}{l}\text { Mixed substrate similar to kitchen } \\
\text { waste }\end{array}$ & $\mathrm{PHB}$ & 70 & Open fed-continuous & [95] \\
\hline
\end{tabular}

Other than the agro-industrial wastes, macroalgal biomass is a non-conventional yet promising feedstock for PHA production. Macroalgae has several advantages such as renewable, independent of land cultivation, and requirement of very less nutrition for growth [70]. Ulva sp., a green macroalgae, is a potential candidate for wastewater remediation. Interestingly, $H f x$. mediterra$n e i$ was capable to produce $55 \%(\mathrm{wt})$ PHBV by utilizing supercritical hydrolysate of Ulva sp. [71]. Thus, this is a double benefitted approach towards value-added polymer synthesis as well as waste remediation. Additionally, recycling of the waste streams emanating from PHA production unit is also a sustainable approach. Koller et al. investigated the possibility to recycle the spent fermentation broth during PHA synthesis by $H f x$. mediterranei using the surplus whey from dairy industry [72]. Interestingly, a considerable part of the fresh PHA fermentation medium could be replaced with the spent fermentation broth. Furthermore, cell debris left after PHA production could replace almost $29 \%$ of the yeast extract in the fresh fermentation process. However, the salty spent fermentation broth might contain inhibitory metabolites which can adversely affect the growth of $H f x$. mediterranei, although, further experimentation and fine-tuning of the process can help to overcome the drawback. 


\section{Low-cost substrate usage by halophilic bacteria}

There are several halophilic bacteria which can efficiently utilize low-cost substrates for PHA production. Spent coffee grounds, the primary waste by-product of coffee processing industry, are still an unusual substrate for valorization. Halomonas halophila was capable of utilizing hydrolysates of spent coffee grounds to produce $61.95 \%$ (wt) of PHB [73]. Furthermore, H. halphila showed the ability to utilize molasses, cheese whey hydrolysates, sawdust hydrolysates, and twice diluted corn stover hydrolysate to produce up to $64 \%$ (wt) PHB. This indicated the robustness of $H$. halphila for PHA production by using inexpensive raw materials. Volatile fatty acids (VFA) are organic compounds that are produced in huge quantity during acidogenic fermentation of food waste or municipal solid waste. $H$. boliviensis inherently produces $\mathrm{PHB}$, however, in presence of VFA mixture containing acetic acid, propionic acid, butyric acid, and valeric acid, it could generate PHBV with $17.5 \mathrm{~mol} \%$ and $8.5 \mathrm{~mol} \% 3 \mathrm{HV}$ fraction in shake flask experiments and 2-L bioreactor, respectively [74]. Wheat bran is a cheap and readily available agricultural residue that gives high potentials to commercial production of PHB. Additionally, anaerobic digest of potato waste is a potent source of acetic and butyric acid. Using wheat bran hydrolysate and digested potato waste, $H$. boliviensis accumulated $43 \%(\mathrm{wt})$ PHB [49]. In a study conducted by Sawant et al., pre-treated corn stover was enzymatically hydrolysed by crude cellulase obtained from co-culture of Trichoderma reesei and Aspergillus niger [75]. The obtained hydrolysate mainly contained glucose, xylose, and cellobiose. This hydrolysate was further used as a feedstock for Paracoccus sp. LL1 (a moderate halophile) and 72.4\% (wt) of PHB was achieved. Interestingly, the PHA yield was higher than that obtained from the sugar mixture containing pure glucose, xylose, and cellobiose. Jatropha curcas is a potential biofuel plant due to the high amounts of oil in its seeds [76]. Halomonas hydrothermalis SM-P-3 M has the ability to utilize the crude glycerol generated during the biofuel production process, without any pre-treatment or $\mathrm{pH}$ adjustment, to produce PHB up to $75 \%$ (wt) [77]. Thus, Jatropha biodiesel by-product, which is otherwise difficult to handle for its impurity and huge quantity, emerged as a possible substrate for PHB production. This is an innovative strategy which can make both the biodiesel and PHA production process economically more feasible. In the subsequent study, the PHA production process was modified to produce PHBV [78]. $\mathrm{K}$-carrageenan, extracted from granular biomass of Kappaphycus alvarezii, was subjected to hydrolysis to obtain SDCLA (seaweed derived crude levulinic acid). 3HV molar fraction ranging from 50 to $80 \mathrm{~mol} \%$ was incorporated into polymer chains when different concentrations of SDCLA were co-fed with the Jatropha biodiesel byproduct. PHA production was inhibited to half when pure levulinic acid was co-fed which indicated that the composition of SDCLA has a vital effect on the PHA accumulation by $H$. hydrothermalis. Thus, application of SDCLA with biodiesel residue is an economical and practical approach towards production of PHA with high 3HV molar fraction.

\section{Effect of fermentation conditions on PHA synthesis in haloarchaea}

Optimizing the fermentation conditions is another key to improve PHA production. Process parameters and substrate feeding strategies are important influencing factors for product synthesis. For instance, Cui et al. cultivated Hfx. mediterranei in synthetic molasses wastewater at different temperatures $\left(15,20,25\right.$, and $\left.35^{\circ} \mathrm{C}\right)$, and found that large quantities of PHA were accumulated at $35{ }^{\circ} \mathrm{C}$ [79]. At high culture temperatures, $H f x$. mediterranei undergoes temperature-driven fast metabolism which causes nitrogen deficiency and triggers PHA overproduction. Thus, the following sections are an overview showing how the physico-chemical parameters and fermentation modes can affect the PHA production in haloarchaea, both quantitatively and qualitatively.

\section{$\mathrm{C} / \mathrm{N}$ ratio}

$H f x$. mediterranei is a well-researched haloarchaeon for PHA synthesis since 1980's. Early investigations on $H f x$. mediterranei have shown that phosphate limitation, nitrogen source, and abundant carbon supply are important factors for accumulating large amounts of PHB (later reconfirmed as PHBV) [28, 80]. These fermentation conditions were also found to be an influencing factor for $3 \mathrm{HV}$ content in PHBV. Hfx. mediterranei produces PHBV containing almost $10 \mathrm{~mol} \%$ of $3 \mathrm{HV}$ inherently from glucose. Ferre-Guell et al. showed that it is possible to obtain PHBV with varying $3 \mathrm{HV}$ content by changing nitrogen source [81]. Ammonium salt enhanced the $3 \mathrm{HV}$ content in the polymer compared to nitrate salt. Moreover, the carbon/nitrogen $(\mathrm{C} / \mathrm{N})$ molar ratio also affected the $3 \mathrm{HV}$ molar fraction in a narrow range. For example, in the presence of ammonium salt, increasing the $\mathrm{C} / \mathrm{N}$ molar ratio from 8 to 34 decreased the $3 \mathrm{HV}$ fraction from 16.9 to $11.7 \mathrm{~mol} \%$. With further increasing the $\mathrm{C} / \mathrm{N}$ ratio to 42 , no $3 \mathrm{HV}$ fraction was observed in PHA. Contrarily, for the nitrate salt, increasing the $\mathrm{C} / \mathrm{N}$ ratio from 8 to 42, only slightly changed the $3 \mathrm{HV}$ fraction from 12.5 to $11.6 \mathrm{~mol} \%$. Thus, altering the nitrogen source and $\mathrm{C} / \mathrm{N}$ ratio can be a helpful strategy to obtain PHBV polymer with different $3 \mathrm{HV}$ contents from $H f x$. mediterranei. A major drawback that lowers the efficiency of $H f x$. mediterranei as a PHA producer is secretion of an 
extracellular polymeric substance (EPS) during PHA production. Simultaneous synthesis of EPS not only increases substrate demand but also adds to production cost. The $\mathrm{C} / \mathrm{N}$ ratio greatly affects the EPS and PHA accumulation [82]. It was observed that increased nitrogen concentration led to enhanced EPS production whereas, nitrogen deficiency promoted PHA accumulation. The percentage of PHA yield coefficient in the sum of EPS and PHA yield coefficients at $\mathrm{C} / \mathrm{N}$ ratio 5 and 35 was 51.32 and $92.8 \%$, respectively. This indicated that most of the carbon source was converted to PHA synthesis during nitrogen limitation.

\section{Salinity effect}

At very high salt concentration, PHA was found to be degraded faster compared to its synthesis in response to high osmotic stress when using activated sludge as inoculum (Paracoccus and Thauera as the dominant genera) [83]. In the early study of Fernandez-Castillo et al., PHA accumulation was higher at $15 \%$ salt concentration than $30 \%$ [28]. Several salt concentrations of 15, 20, 25 and 30\%, were further tested on PHA accumulation in $H f x$. mediterranei. It was clarified that the total salt (containing $\mathrm{NaCl}, \mathrm{MgCl}_{2}, \mathrm{MgSO}_{4}, \mathrm{CaCl}_{2}, \mathrm{KCl}, \mathrm{NaHCO}_{3}$ and $\mathrm{NaBr}$ ) at a concentration of $25 \%$ was optimal for PHA accumulation [80]. Similarly, Alsafadi et al. found salt concentration of $22 \%$ to be better than $30 \%$ for PHA accumulation in $H f x$. mediterranei [62]. Recently, salinity was found to be a parameter influencing EPS and PHA accumulation in $H f x$. mediterranei [84]. Increasing $\mathrm{NaCl}$ concentration from 7.5 to $25 \%$ slightly decreased EPS production from 371.36 to $319.74 \mathrm{mg} / \mathrm{g}$ CDW, whereas PHA content increased from 46.7 to $71.1 \%$ of CDW in this strain. High salinity tends to divert carbon towards polymer storage by disrupting EPS synthesis in $H f x$. mediterranei.

\section{Feeding strategy}

When $H f x$. mediterranei was cultivated in a fed-batch fermentation by feeding extruded cornstarch and yeast extract at a ratio of $1 / 1.7(\mathrm{~g} / \mathrm{g})$, a CDW of $39.4 \mathrm{~g} / \mathrm{L}$ containing 50.8\% (wt) PHBV was obtained [85]. During this fermentation process, a $\mathrm{pH}$-stat controlled feeding system was applied to maintain the $\mathrm{pH}$ value at 6.9-7.1. The same feeding strategy was further followed when extruded rice and extruded cornstarch at an optimized ratio of $1: 8(\mathrm{~g} / \mathrm{g})$ was fed to $H f x$. mediterranei in repeated fed-batch fermentation [86]. A CDW of $140 \mathrm{~g} / \mathrm{L}$ containing $55.6 \%$ (wt) of PHBV was obtained, indicating that the developed process was potentially more economical for semi-continuous fermentation at large-scale. Hgn. amylolyticum efficiently produces PHBV containing $20.1 \mathrm{~mol} \% 3 \mathrm{HV}$ from glucose, which is the highest $3 \mathrm{HV}$ fraction reported among haloarchaeal species [46]. However, CDW and PHBV concentration was only $5.9 \mathrm{~g} / \mathrm{L}$ and $1.5 \mathrm{~g} / \mathrm{L}$, respectively in batch mode. In order to improve PHBV productivity, fed-batch fermentation was employed where glucose was supplemented up to $10 \mathrm{~g} / \mathrm{L}$ once residual glucose concentration dropped below $0.5 \mathrm{~g} / \mathrm{L}$. This fed-batch technique enhanced CDW to $29 \mathrm{~g} / \mathrm{L}$ and PHBV concentration to $14 \mathrm{~g} / \mathrm{L}$ [46].

\section{Effect of process parameters on PHA synthesis in halophilic bacteria}

Stanley et al. optimized the nutritional requirements and process parameters for PHA production using Halomonas venusta KT832796 in 2-L bioreactor [87]. This strain produced CDW of $3.86 \mathrm{~g} / \mathrm{L}$ containing $70.56 \%$ (wt) PHB at a volumetric productivity of $0.160 \mathrm{~g} / \mathrm{L} / \mathrm{h}$ by using glucose $(20 \mathrm{~g} / \mathrm{L})$ and ammonium citrate $(2 \mathrm{~g} / \mathrm{L})$. A further fed-batch cultivation using four different feeding strategies was employed [87]. During carbon limitation, the $\mathrm{pH}$ value of medium increases due to build-up of ammonium ions [88]. Thus, the first strategy was based on $\mathrm{pH}$ signal where feed pump was manually switched on as $\mathrm{pH}$ increased above 7.0 [87]. The PHB volumetric productivity significantly increased to $0.257 \mathrm{~g} / \mathrm{L} / \mathrm{h}$ but the PHB content decreased to $39.15 \%$ (wt) as the carbon flux got diverted towards biomass synthesis yielding $\mathrm{CDW}$ of $87.3 \mathrm{~g} / \mathrm{L}$. In the second strategy, residual glucose concentration in the feed was controlled at $10-20 \mathrm{~g} / \mathrm{L}$. CDW of $25.7 \mathrm{~g} / \mathrm{L}$ containing $58.36 \%$ (wt) of PHB was obtained with the volumetric productivity maintained at $0.156 \mathrm{~g} / \mathrm{L} / \mathrm{h}$. In the third strategy, the residual glucose concentration was controlled at $20-50 \mathrm{~g} / \mathrm{L}$. Under this condition, PHA content of $76.67 \%$ from a CDW of $29.45 \mathrm{~g} / \mathrm{L}$ was obtained. However, the PHB volumetric productivity further decreased to $0.138 \mathrm{~g} / \mathrm{L} / \mathrm{h}$. In the fourth strategy, a high concentration of glucose close to $100 \mathrm{~g} / \mathrm{L}$ was fed as a single pulse and, once utilized, feed was supplied so that the residual glucose concentration was maintained at $1-2 \mathrm{~g} / \mathrm{L}$. This strategy helped to maintain the $\mathrm{pH}$ value at 7.0. A net PHB content of $88.12 \%$ from a CDW of $37.9 \mathrm{~g} / \mathrm{L}$ was achieved. Furthermore, $\mathrm{PHB}$ volumetric productivity of $0.248 \mathrm{~g} / \mathrm{L} / \mathrm{h}$ was attained, which was almost comparable to $\mathrm{pH}$-signal based strategy. This work is an explicit example showing how feeding methods can enhance PHB productivity.

Halomonas boliviensis, can accumulate PHB when cultivated on different sugar sources. However, one of its drawbacks is the low cell density which results in low PHA productivity. Optimization of the process parameters showed that oxygen depletion in the presence of excess carbon source led to seven-fold increase in cell mass. Using this strategy, an improved CDW of $14 \mathrm{~g} / \mathrm{L}$ containing 54\% (wt) PHB was obtained, which 
was comparable with the PHA production reported by other non-halophilic producers in batch systems [89]. Additionally, in a fed-batch cultivation mode, effects of nitrogen and phosphorous sources were studied to optimize the $\mathrm{PHB}$ production in $\mathrm{H}$. boliviensis [90]. $\mathrm{NH}_{4} \mathrm{Cl}$ and $\mathrm{K}_{2} \mathrm{HPO}_{4}$ were added to the medium during the initial hours of cultivation to favour cell growth. Monosodium glutamate, a cheap replacement of yeast extract, was further added for faster consumption of $\mathrm{NH}_{4} \mathrm{Cl}$. After attaining cell growth, feeding of these salts were suppressed to promote PHB accumulation. This strategy led to a $44 \mathrm{~g} / \mathrm{L}$ of CDW containing $81 \%$ (wt) PHB, illustrating it to be an efficient approach for obtaining high PHA production. Using the similar strategy, co-production of $42.47 \mathrm{~g} / \mathrm{L}$ of PHB and $4.3 \mathrm{~g} / \mathrm{L}$ of ectoine was further realized in a process comprising of two fed-batch cultures [91]. The culture condition of the first fed-batch system was conducive for high cell mass. Cells from the first fed-batch culture were harvested during the exponential phase and transferred into the second fed-batch culture. Nitrogen and phosphate supply were limited in the second fed-batch culture which favoured product formation. Ectoine was synthesized during the exponential phase whereas PHB was synthesized during the late exponential phase and stationary phase. Co-production of the two metabolites from a single fermentation unit is a promising strategy which would lower the production cost of the respective molecules. Simultaneous Saccharification and Fermentation (SSF) methodology is an energy efficient technique commonly used in the first generation biorefinery. To integrate PHA production into the biorefinery scheme, SSF technique was employed to produce PHB by $H$. boliviensis using corn mash as carbon source [92]. Interestingly, $\mathrm{PHB}$ production was $60 \%$ higher using SSF mode than Separate Hydrolysis and Fermentation (SHF) mode wherein corn mash was saccharified separately before fermentation. Additionally, SSF mode required less inoculum volume, single reaction vessel and moreover, saved $47 \%$ of the overall processing time. In 2015, Air-Lift Reactors (ALR) was successfully employed to produce $41 \%$ (wt) PHB from H. boliviensis by using starch hydrolysate and monosodium glutamate as the respective carbon and nitrogen source [93]. Although the obtained PHB content was lower compared to fed-batch reactors, ALR has the advantages of reduced construction and operational costs.

PHBV production by H. campisalis MCMB-1027 at different aeration and agitation in 14-L fermentor revealed that controlling dissolved oxygen is important for enhancing PHA production [94]. When dissolved oxygen was controlled within a range of $1-5 \%$ after attainment of growth phase, PHBV accumulation increased to $56.23 \%$ (wt) compared to $42.06 \%$ (wt) under uncontrolled condition. However, too low CDW of $1.33 \mathrm{~g} / \mathrm{L}$ containing 49.17\% (wt) PHBV was obtained when fermentation was scaled up to $120-\mathrm{L}$ fermentor by keeping dissolved oxygen maintained at $1-5 \%$.

\section{Effect of fermentation apparatus on PHA synthesis}

One of the exclusive advancements in PHA research is employment of open, unsterile, and continuous fermentation process for PHA production by halophiles. Application of open fermentors is an effective strategy for low-cost PHA production mainly due to reduced sterility requirement. Tan et al. carried out a 14-day unsterile fermentation of $H$. bluephagenesis TD01 using fed-batch and continuous feeding methods [51]. The process involved two fermentors. Cells collected from the first fermentor were pumped into the second fermentor for promoting PHA accumulation by maintaining nitrogen limitation in medium. $40 \mathrm{~g} / \mathrm{L}$ of CDW containing 60\% (wt) PHB was obtained from the first fermentor whereas $20 \mathrm{~g} / \mathrm{L}$ of CDW containing 65\% (wt) PHB was obtained in the second. This process aims at lowering cost and saving energy as the overall process does not involve any sterilization step and tap-water is used instead of distilled water. Moreover, use of two or more fermentors together brings up a possibility to obtain different types of PHA if different substrates are provided. Furthermore, when Halomonas campaniensis strain LS21 was cultured in an open and continuous sea-water based fermentation process, it could grow in a mixed substrate, whose constituent was similar to kitchen wastes, such as soluble and insoluble cellulose, proteins, fats, fatty acids, and starch [95]. During a 65-day fermentation process, a maximal CDW of $73 \mathrm{~g} / \mathrm{L}$ and PHB content up to $70 \%$ (wt) were obtained without any contamination. Thus, H. campaniensis strain LS21 is another potential halophile for long-lasting, low-cost, and bulk production of PHB.

Other than low cost and enhanced production, efficient commercial scale fermentation also requires easy detection and determination of product formation. The methods available for PHA detection and determination are tedious and time-consuming [96]. Flow cytometry (FC) is a fully-automated and multiparametric technique for PHA determination. It rapidly and precisely studied PHB accumulation in a clear correlation with PHB concentration measured by GC-analysis in H. boliviensis [97]. FC also distinguished between two bacterial populations on the basis of presence or absence of PHB. Thus, implementations of FC in PHA production will not only allow monitoring the time for maximal productivity in a short time but will also save time for sample preparation. 


\section{PHA metabolism and its regulation in halophiles}

PHA metabolism involves its biosynthesis and degradation processes. PHA biosynthesis in halophiles has been extensively studied to reveal the synthetic pathways leading to production of different kinds of PHA $[98,99]$. Three classical enzymes directly involved in $\mathrm{PHB}$ or PHBV synthesis include $\beta$-ketothiolase (PhaA), $\beta$-ketoacyl-CoA reductase $(\mathrm{PhaB})$, and PHA synthase (PhaC). In contrast, PHA depolymerase (PhaZ) is mainly responsible for PHA mobilization. Rigorous researches have shown the immense diversity of PHA metabolic enzymes and pathways, based on the kind of halophile as well as the substrate utilized [16]. The regulation of PHA metabolism is a complex phenomenon with only a few studies reported in halophiles. Among haloarchaea, several novel proteins including PhaEC, PhaA/BktB, PhaP, PhaR, PhaZ, BdhA (3HB dehydrogenase) and PhaJ $((R)-$ specific enoyl-CoA hydratase) (Table 5 ), and four novel propionyl-CoA supplying pathways have been identified and characterized. In this section, we will attempt to summarize the important genes, proteins, and pathways involved in PHA metabolism and its regulation in halophiles to provide a bird's eye view of the PHA research to the readers.

\section{Diversity of PHA gene clusters in halophiles}

The PHA-related genes are generally organized into clusters but their arrangements are highly diversified. Mostly, the PHA gene cluster is conserved within haloarchaea and organised as maoC-phaR-phaP-phaE-phaC [100]. Compared to this, halophilic bacteria display significant differences. $H$. elongata DSM2581 and Halomonas sp. O-1 demonstrated a genetic organization of phaP1phaP$2 p h a C 1$ where the two phasin proteins encoded by phaP1 and phaP2 constituted the structural proteins of the PHA granules [101]. Halomonas sp. SF2003 is another PHAproducing species belonging to the Halomonadaceae family [102]. It was noteworthy that the PHA related genes including phaA, phaB, phaC1/phaC2, and phaR were not clustered in one operon rather were located distantly apart from each other [103]. In the genome of $H$. bluephagenesis TD01, only phaP and phaC1 were connected by a space of $92 \mathrm{bp}$ whereas all other genes were scattered in the genome [52]. However, phaC1 had an independent promoter which suggested that phaP and phaC1 were separately transcribed driven by their own promoters. These cluster organizations might provide useful evidences about the evolution of the PHA-related genes among different groups of halophiles.

\section{PHA synthase}

PHA synthase is the key enzyme involved in PHA biosynthesis that functions by polymerizing the hydroxyalkanoate monomers into PHA chains. In haloarchaea, PHA synthase is composed of two subunits, PhaC and PhaE, and belongs to Class III type. In contrast, PHA synthase in halophilic bacteria consists of only PhaC subunit and belongs to Class I type, which is similar to most of the PHA-accumulating bacteria. Haloarchaeal PHA synthase possesses several novel features that have been discussed in the following paragraphs.

In 2002, archaeal PHA synthase activity was detected for the first time in extremely halophilic archaeon named as strain 56 [34]. PHA synthase was covalently associated with $\mathrm{PHB}$ granules and its expression was found to be induced only in the condition of PHB accumulation. However, due to the lack of sequence similarity, molecular characterization of the enzymes was not possible. With the help of complete genome sequence of Har. marismortui, Han et al. investigated the molecular characterization of its PHA synthase genes for the first time within Archaea domain [104]. The annotated PhaC protein contained the highly conserved lipase box-like sequence (Gly-X-Cys-X-Gly-Gly), the amino acid triad (Cys162-Asp317-His346), and the conserved motif of class III PHA synthase (Arg-Met-Glu-X-Trp-Ile-XAsp-X-X-Asp). These features showed its high similarity with bacterial class III PHA synthases, indicating that the annotated PhaC might be a subunit of class III PHA synthase in Har. marismortui. Interestingly, the protein encoded by the open reading frame immediately upstream of the phaC gene contained the conserved "PhaE box" and the encoded protein showed 21 to $25 \%$ identity with the PhaE subunits of bacterial class III PHA synthases. Thus, this open reading frame was designated as phaE gene. Har. hispanica, a phylogenically close archaeon to Har. marismortui, consisted of highly homologous phaEC genes and produced 9.9\% (wt) of PHB [104]. Only coexpression of phaC and phaE in $\triangle$ phaEC mutant strain restored the PHA accumulation in Har. hispanica. Interestingly, unlike the haloarcheon strain 56, the PHA synthase was expressed even when Haloarcula cells were not cultured in PHA-accumulating medium. However, only the $\mathrm{PhaC}$ protein was found to be stably attached to the PHA granules whereas PhaE was not. This phenomenon indicated that $\mathrm{PhaC}$ and $\mathrm{PhaE}$ subunits constituted a novel form of class III PHA synthase in Haloarcula species.

Similarly, the PHA synthase of $H f x$. mediterranei is also composed of PhaE and PhaC subunits and both the proteins constitutively expressed in nutrient-limited as well as nutrient-rich media [41]. In 2015, the PHA synthase from Hgn. amylolyticum TNN58 was characterized and it was reported that the phaE and phaC genes constituted an operon [46]. The amino acid sequence of PhaE and PhaC from TNN58 showed 64\% and 62\% identity 
Table 5 Summary of key enzymes and proteins involved in PHA metabolism and regulation identified from halophiles

\begin{tabular}{|c|c|c|c|c|c|}
\hline Process & Proteins & Organism & & Features & Refs. \\
\hline \multirow[t]{20}{*}{ PHA synthesis } & \multirow[t]{4}{*}{ PhaEC } & \multirow[t]{8}{*}{ Haloarchaea } & Haloarcula marismortui & \multirow{3}{*}{$\begin{array}{l}\text { Class III type; constitutes the active PHA synthase; co-transcription; } \\
\text { constitutive expression; conserved lipase box-like sequence, } \\
\text { amino acid triad (Cys-Asp-His), conserved motif of class III PHA } \\
\text { and longer C-terminal sequence }\end{array}$} & {$[104]$} \\
\hline & & & Haloarcula hispanica & & {$[104]$} \\
\hline & & & Haloferax mediterranei & & {$[41]$} \\
\hline & & & $\begin{array}{l}\text { Halogranum amylolyticum } \\
\text { TNN58 }\end{array}$ & $\begin{array}{l}\text { Conserved lipase box-like sequence and catalytic triad residues; } \\
64 \% \text { and } 62 \% \text { identity with PhaE and PhaC from Hfx. mediterranei }\end{array}$ & {$[46]$} \\
\hline & PhaC1 & & Haloferax mediterranei & $\begin{array}{l}\text { Lipase box-like sequence, conserved motif of class III PHA synthase } \\
\text { and longer C-terminal sequence }\end{array}$ & {$[105]$} \\
\hline & PhaC2 & & & $\begin{array}{l}\text { Ala instead of the last Gly in lipase box-like sequence; conserved } \\
\text { motif not strongly conserved; longer C-terminal sequence miss- } \\
\text { ing, without PhaC function }\end{array}$ & {$[105]$} \\
\hline & $\mathrm{PhaC} 3$ & & & $\begin{array}{l}\text { Lipase box-like sequence, conserved motif of class III PHA synthase } \\
\text { and longer C-terminal sequence }\end{array}$ & {$[105]$} \\
\hline & PhaC & & Halorubrum lacusprofundi & $\begin{array}{l}\text { High abundance at low temperature; C-terminal has 47\% identity } \\
\text { with the C-terminal of Haloferax mediterranei PhaC }\end{array}$ & [38] \\
\hline & \multirow[t]{4}{*}{ PhaC } & \multirow[t]{6}{*}{ Halophilic bacteria } & Halomonas elongata DSM2581 & \multirow{2}{*}{$\begin{array}{l}\text { Two candidate genes; phaCl is functional; unique serine instead } \\
\text { of the first glycine in lipase box-like sequence; PhaC1 has affinity } \\
\text { towards both } 3 \mathrm{HB} \text { and } 3 \mathrm{HV} \text { monomers }\end{array}$} & \multirow[t]{2}{*}[101]{} \\
\hline & & & Halomonas sp. O-1 & & \\
\hline & & & Halomonas sp. R5-57 & Three candidate encoding genes; the third PhaC is truncated & {$[106]$} \\
\hline & & & Yangia sp. CCB-MM3 & Class I type; two candidate encoding genes & {$[107]$} \\
\hline & PhaC1 & & \multirow[t]{2}{*}{ Halomonas bluephagenesis TD01 } & $\begin{array}{l}\text { Conserved catalytic triad (Cys-Asp-His) and the conserved lipase } \\
\text { box-like; Ser instead of first Gly in lipase box-like sequence }\end{array}$ & \multirow[t]{2}{*}[52]{} \\
\hline & $\mathrm{PhaC2}$ & & & $\begin{array}{l}\text { Conserved catalytic triad (Cys-Asp-His) and the conserved lipase } \\
\text { box-like; longer C-terminus; shorter N-terminus; Ala instead of the } \\
\text { last Gly in lipase box-like sequence }\end{array}$ & \\
\hline & BktB & \multirow[t]{2}{*}{ Haloarchaea } & \multirow[t]{2}{*}{ Haloferax mediterranei } & \multirow{2}{*}{$\begin{array}{l}\text { Two subunits, } a \text { and } \beta ; a \text { is the catalytic subunit and the catalytic } \\
\text { residues are Ser-His-His; } \beta \text { subunit comprises of oligo-sachharide } \\
\text { binding domain }\end{array}$} & \multirow[t]{2}{*}{ [109] } \\
\hline & PhaA & & & & \\
\hline & PhaA & Halophilic bacteria & Halomonas elongata BK-AG18 & One subunit, catalytic residues are Cys-His-Cys & [112] \\
\hline & \multirow[t]{3}{*}{ PhaB } & \multirow[t]{2}{*}{ Haloarchaea } & Haloferax mediterranei & $\begin{array}{l}\text { NADPH-dependent; two candidate encoding genes, phaB1 and } \\
\text { phaB2; PhaB1 and PhaB2 responsible for } 3 \mathrm{HB}-\mathrm{CoA} \text { and } 3 \mathrm{HV}-\mathrm{Co} \mathrm{A} \\
\text { formation }\end{array}$ & [113] \\
\hline & & & Haloarcula hispanica & NADPH-dependent; only FabG 1 responsible for PHA synthesis & [114] \\
\hline & & Halophilic bacteria & Halomonas bluephagenesis TD01 & $\mathrm{NADH}$-dependent & [115] \\
\hline \multirow[t]{4}{*}{ PHA regulation } & \multirow[t]{2}{*}{ PhaP } & Haloarchaea & Haloferax mediterranei & $\begin{array}{l}\text { Consists of conserved amino acids and aspartate/glutamate rich } \\
\text { regions in C-terminal; lysine acetylated }\end{array}$ & {$[117,119]$} \\
\hline & & Halophilic bacteria & Halomonas bluephagenesis TD01 & $\begin{array}{l}\text { Three candidate encoding genes; only PhaP1 responsible for the } \\
\text { amount and size of PHA granules }\end{array}$ & {$[116]$} \\
\hline & \multirow[t]{2}{*}{ PhaR } & Haloarchaea & Haloferax mediterranei & $\begin{array}{l}\text { Consists of } \mathrm{AbrB} \text { (antibiotic resistance protein B) — like domain; } \\
\text { regulates function of PhaP }\end{array}$ & [118] \\
\hline & & Halophilic bacteria & Halomonas bluephagenesis TD01 & $\begin{array}{l}\text { Regulates PHA synthesis; amphiphilic property; strong and robust } \\
\text { emulsifier }\end{array}$ & {$[98,116]$} \\
\hline \multirow[t]{6}{*}{ PHA degradation } & PhaZh1 & \multirow[t]{3}{*}{ Haloarchaea } & \multirow[t]{3}{*}{ Haloferax mediterranei } & Palatin-like protein; Contains classical lipase box-like & [121] \\
\hline & BdhA & & & $\begin{array}{l}\text { Encoding gene located upstream of phaZh 1; hydrolyses 3HB mono- } \\
\text { mers generated by PhaZ1 from natural PHA granules }\end{array}$ & [121] \\
\hline & PhaJ & & & Dehydrates 3-hydroxyacyl-CoA to enoyl-CoA & {$[100]$} \\
\hline & PhaZ1 & \multirow[t]{3}{*}{ Halophilic bacteria } & \multirow[t]{3}{*}{ Halomonas bluephagenesis TD01 } & \multirow[t]{2}{*}{ Lacks signal peptide, intracellular depolymerase } & \multirow[t]{3}{*}[52]{} \\
\hline & PhaZ2 & & & & \\
\hline & PhaZ3 & & & Signal peptide present, extracellular depolymerase & \\
\hline
\end{tabular}

with the counterparts from $H f x$. mediterranei. Moreover, the PhaC subunit from TNN58 contained the conserved lipase box-like sequence (Gly-X-Cys-X-Gly-Gly) and the catalytic triad residues (Cys150-Asp305-His333). In 2017, a multi-domain protein showing $47 \%$ sequence identity in its C-terminal region with the C-terminal of $H f x$. mediterranei $\mathrm{PhaC}$ was identified in Hrr. lacusprofundi
[38]. Interestingly, this haloarchaeon is known to produce PHA at low temperatures as higher abundances of PhaC proteins were observed at low temperatures.

The molecular weight of haloarchaeal $\mathrm{PhaE}$ and $\mathrm{PhaC}$ was found to be $20 \mathrm{kDa}$ and 50.1 to $58.5 \mathrm{kDa}$, respectively, which greatly differed from bacterial class III PHA synthase $(40 \mathrm{kDa})$ [35]. Compared to bacterial PhaC, 
haloarchaeal PhaC consists of a longer C-terminal [35, 41]. This longer $\mathrm{C}$-terminus is indispensable for a fully active PHA synthase as its truncation led to less accumulation of PHA. The longer $\mathrm{C}$-terminal was found when PHA synthase in 18 other strains belonging to 12 haloarchaeal genera was investigated [35]. In addition to the catalytic triad (C162-D317-H346), haloarchaeal PhaC subunit also possesses two additional residues (C143 and C190), important for its enzymatic activity [35]. Moreover, unlike bacterial PhaE subunit, PhaE box was only present in Haloarcula and Halorhabdus utahensis DSM 12940, indicating that this box is not so conserved in haloarchaeal PhaEs. The alignment and phylogenetic analysis of the conserved sequences of haloarchaeal and bacterial PHA synthase distinctly clustered them into two separate domains [35]. These findings clearly suggest that haloarchaeal PHA synthase constitutes a novel subtype of class III PHA synthase.

Interestingly, besides the phaC gene clustered with phaE, the whole genome sequence analysis presented three additional phaC paralogs (designated as phaC1, phaC2 and phaC3) in Hfx. mediterranei [105]. All the PhaC proteins exhibited $43-58 \%$ identity and contained the amino acid triad (Cys-Asp-His). Similar to PhaC, $\mathrm{PhaC} 1$ and $\mathrm{PhaC} 3$ contained the lipase box-like sequence, the conserved motif for class III PHA synthase as well as the longer $\mathrm{C}$-terminal sequence. However, in the case of PhaC2, lipase box-like sequence contained an "Ala" residue instead of the last "Gly" residue. Furthermore, the conserved motif was not strongly conserved and the longer C-terminal sequence was missing in PhaC2. Although the three additional genes were not transcribed during PHBV accumulation, the heterologous expression of $H f x$. mediterranei PhaE with each of the PhaC genes in a PHA synthase gene deleted strain, Har. hispanica PHB1 , led to accumulation of PHBV with varied 3HV content, except PhaC2. Phylogenetic tree analysis based on the four PhaCs from Hfx. mediterranei and PhaCs from other haloarchaea revealed that only $\mathrm{PhaC}$ was closely related to other haloarchaeal PhaCs whereas the three additional $\mathrm{PhaC}$ might have evolved by horizontal transfer from other source and not directly from PhaC of $H f x$. mediterranei.

In the case of halophilic bacteria, PHA synthase shows some significant differences with the haloarcheal PHA synthase. Most importantly, PHA synthase of halophilic bacteria belongs to class I type and is composed of only one subunit, PhaC. H. elongata DSM2581 and Halomonas sp. O-1 have two phaC candidate genes, phaC1 and phaC2 [101]. Expression of only PhaC1 in E. coli JM109 led to the accumulation of PHB proving phaC1 to be the primary functional gene. Notably, the lipase boxlike sequence in the Halomonas $\mathrm{PhaC} 1$ is comprised of unique serine instead of the first glycine (Ser-X-Cys-XGly), which is another significant difference with haloarchaeal PhaCs. Substitution of this serine with glycine did not affect PHB content. However, substitution of the central cysteine by alanine completely abolished PHB accumulation, indicating it to be the catalytic cysteine of $\mathrm{PhaC} 1$. Interestingly, expression of $\mathrm{PhaC} 1$ in a non PHAaccumulating mutant of $R$. eutropha in the presence of sodium valerate led to PHBV synthesis, suggesting the affinity of PhaC1 towards both $3 \mathrm{HB}$ and $3 \mathrm{HV}$ monomers. The genome of Halomonas sp. R5-57, a marine member of the Halomonadaceae family, has three genes annotated as phaC [106]. PhaC (HALO1802) showed 91\% and $86 \%$ homology with PhaC1 of H. boliviensis and H. campaniensis, respectively. The second PhaC, HALO2716, differed from $\mathrm{PhaC} 1$ but showed $75 \%$ homology with another $\mathrm{PhaC}$ from $H$. boliviensis. The third $\mathrm{PhaC}$ encoded by loci HALO3139 and HALO3140 was truncated, generating stop codon after 67 amino acids. Recently, Yangia sp. CCB-MM3, isolated from soil sediment in the estuarine possessed two PHA synthase genes, phaC1 $1_{Y s}$ and $p h a C 2_{Y S}$, located on chromosome 1 and 2, respectively [107]. Both of them encoded 598-amino acid proteins. Similar to Halomonas sp., Yangia PHA synthase consisted of only one subunit and belonged to class I PHA synthase.

Interestingly, new PHA synthase even exists among the halophilic bacteria. The genome of $H$. bluephagenesis TD01 consisted of two putative genes encoding PhaC [52]. PhaC1 showed almost $44 \%$ and $34 \%$ sequence similarity with the PHA synthase from $R$. eutropha H16. Furthermore, its molecular mass was found to be about $70 \mathrm{kDa}$, which was within the range of classical Class I PHA synthase $(61-73 \mathrm{kDa})$. However, $\mathrm{PhaC} 2$ from the $H$. bluephagenesis TD01 showed some differences from the classical PHA synthase. First, the molecular mass of PhaC2 and its homologues from H. elongata DSM 2581, Chromohalobacter salexigens DSM 3043, and Aromatoleum aromaticum EbN1 were between 81 and $92 \mathrm{kDa}$, which was higher than the classical class I PHA synthase. Second, in the phylogenetic analysis, the common ancestor for PhaC2 from strain TD01 and its homologues were distantly clustered from the well characterized PHA synthases. Third, compared to classical class I PHA synthase, $\mathrm{PhaC} 2$ displayed a longer $\mathrm{C}$-terminus and a shorter $\mathrm{N}$-terminus. Nevertheless, the conserved catalytic triad (Cys-Asp-His) and the conserved lipase box-like were recognized in both $\mathrm{PhaC} 1$ and $\mathrm{PhaC} 2$. Interestingly, instead of the traditional lipase box-like amino acids, Gly-X-Cys-X-Gly, PhaC1 contained Ser-X-Cys-X-Gly and PhaC2 contained Gly-X-Cys-X-Ala. These differences indicate the presence of new PHA synthases in the halophilic bacteria. 
Understanding the biochemical properties and the underlying catalytic mechanisms of the PhaCs will definitely enhance the biotechnological applications of these halophilic strains. Microbial mats are highly diversified microbial community which commonly accumulate high quantities of PHA. Interestingly, in a recent study, Martínez-Gutiérrez et al. identified six PHA-producing strains from hypersaline microbial mats, of which three belonged to Halomonas species [108]. Their PCR amplicons using primers specific to $p h a C$ gene showed high identity values (94-97\%) with class I PHA synthase of Halomonas aestuarii. Microbial mats are a potential source for identifying new PHA-producing strains. Thus, the genomic reports already available will be useful for comparative genome analysis of new PHA-producing halophiles.

\section{$\beta$-ketothiolase}

During PHA synthesis, two acety-CoA molecules are condensed to one acetoacetyl-CoA molecule by the $\beta$-ketothiolase enzyme. In halophilic bacteria, $\beta$-ketothiolase is composed of a single subunit, PhaA, whereas haloarcheal $\beta$-ketothiolase is composed of two subunits. Moreover, the amino acid residues in their catalytic subunits are distinct.

Bioinformatic and genetic analysis revealed that the $\beta$-ketothiolase enzyme responsible for PHBV accumulation in $H f x$. mediterranei was encoded by two sets of cotranscribed genes, designated as $b k t B \alpha \beta$ and $p h a A \alpha \beta$ [109]. PhaA could only produce acetoacetyl-CoA through condensation of two acetyl-CoA molecules. Interestingly, BktB catalyzed the production of 3-ketovaleryl-CoA through condensation of acetyl-coA and propionyl-coA, along with acetoacetyl CoA formation. BktB $\alpha$ and PhaA $\alpha$ were the catalytic subunits due to the presence of the thiolase domain. The catalytic residues of these subunits comprised of "Ser-His-His" in contrary to the bacterial "Cys-His-Cys". The other subunit, i.e., BktB $\beta$ and PhaA $\beta$, contained oligo-sachharide binding domain which are indispensable for the $\beta$-ketothiolase activity as deletion of this domain in both $\mathrm{BktB} \beta$ and PhaA $\beta$ completely abolished PHA synthesis. However, the $\mathrm{N}$ - and C-terminal regions of the $B k t B \beta$ and $P h a A \beta$ had differential effects on the enzymatic activity. Deletion of the C-terminal of $B k t B \beta$ reduced PHA synthesis by $70 \%$ but effect was not so significant for its N-terminal deletion. Contrarily, N-terminal deletion in PhaA $\beta$ reduced PHA synthesis by $93 \%$ and $\mathrm{C}$-terminal deletion led to a complete loss of PHA synthesis. Thus, C-terminal is indispensable for both the $\beta$-subunits but $\mathrm{N}$-terminal is essential for only PhaA $\beta$ activity. Furthermore, construction of hybrid enzyme, i.e, BktB $\alpha-P h a A \beta$ and PhaA $\alpha-B k t B \beta$ demonstrated that $\alpha$-subunits determined the substrate specificity and $\beta$-subunits were functionally interchangeable. This can be explained by the fact that $B k t B \alpha-P h a A \beta$ could accumulate PHBV whereas PhaA $\alpha$-BktB $\beta$ accumulated PHB. Thus, BktB $\alpha-P h a A \beta$ and PhaA $\alpha-B k t B \beta$ have similar substrate specificity like $B k t B$ and PhaA, respectively. However, knockout strain of $b k t B \beta$ could accumulate only PHB. Only by increasing the expression level of PhaA $\beta$ restored the PHBV accumulation ability. This implied that PhaA $\beta$ inherently prefers interacting with PhaA $\alpha$ over $B k t B \alpha$ to form an active $\beta$-ketothiolase.

In halophilic bacteria, PhaA is a classical $\beta$-ketothiolase similar to that of bacteria. This enzyme is composed of a single subunit. A few halomonas species and engineered $H$. bluephagenesis TD01 have the ability to accumulate PHBV from unrelated carbon source and thus their PhaA enzyme could condense acetyl CoA or acetyl$\mathrm{CoA}$ and propionyl-CoA to generate acetoacetyl-CoA or 3-ketovaleryl-CoA [56, 98, 110, 111]. The protein structure of the putative PhaA of $H$. elongata BK-AG18 showed $68.72 \%$ identity to the $\beta$-ketothiolase structure of Ralstonia eutropha H16. Furthermore, the residues Cys88, His348, and Cys378 were identified to be the catalytic residues of PhaA, which is similar to the bacterial $\beta$-ketothiolase but different from the haloarcheal $\beta$-ketothiolase [112].

\section{$\beta$-ketoacyl-CoA reductase}

The generated 3-ketoacyl-CoA is further reduced to (R)-3-HB-CoA and/or $(R)-3$-HV-CoA by a PHA specific 3-ketoacyl-CoA reductase (PhaB). PhaB uses NAD(P) $(\mathrm{H})$ as a cofactor during this process. Most of the identified PhaB enzymes use NADPH as the cofactor. The PhaB enzyme from $H$. bluephagenesis TD01 utilizes NADH instead of NADPH as its cofactor.

$H f x$. mediterranei genome encodes two PhaB proteins namely, PhaB1 and PhaB2 [113]. Knocking out of phaB1 did not affect PHBV synthesis. However, phaB2 knockout significantly decreased PHA synthesis and the 3HV monomer fraction in the polymer. Strikingly, knockout of phaB1 and phaB2 in combination completely abolished PHBV synthesis. Thus, PhaB1 has no obvious function in the presence of $\mathrm{PhaB2}$; whereas $\mathrm{PhaB} 1$ is responsible for precursor supplying when phaB2 was knocked out. Like PhaB, FabG belongs to the short-chain dehydrogenase/ reductase (SDR) superfamily. The genomes of Har. marismortui ATCC 43049 and Har. hispanica encode multiple FabG paralogs but their amino acid identity with the bacterial counterpart is quite low, ranging from 25 to $38 \%$ [114]. Under both nutrient-rich and nutrient-limiting conditions, all the $f a b G$ paralogs were transcribed, however, disruption of only fabG1 abolished PHA synthesis in Har. hispanica. Further complementation of the fabG1 gene restored PHA synthesis. Intriguingly, coexpression 
of fabG1 and phaEC in Hfx. volcanii DS70, a non PHAaccumulating haloarchaeon, resulted in PHA accumulation. However, coexpression of other $f a b G$ paralogs with phaEC could not lead to PHA synthesis in $H f x$. volcanii DS70. Additionally, biochemical analysis revealed that disruption of fabG1 decreased the NADPH-dependent acetoacetyl-CoA reductase activity. Whereas, disruption of other $f a b G$ genes neither affected NADPH- nor NADP-dependent acetoacetyl-CoA reductase activity. Thus, this investigation unquestionably demonstrated that fabG1 encoded the PhaB protein in Haloarcula genus.

Bioinformatics analysis predicted one phaB gene in halophilic bacterium, H. bluephagenesis TD01 $[115,116]$. Interestingly, the $\mathrm{NAD}(\mathrm{P})(\mathrm{H})$ binding domain of PhaB had a glutamate which was crucial for hydrogen bond formation with hydroxyl groups on the adenine ribose of $\operatorname{NAD}(\mathrm{H})$. The specific activity of PhaB towards NADH (30.67 mU/mg) was significantly higher than NADPH $(1.71 \mathrm{mU} / \mathrm{mg})$, indicating that $\mathrm{PhaB}$ from $H$. bluephagenesis TD01 is NADH-dependent.

\section{Propionyl-CoA synthetic pathway}

Among haloarchaea, $H f x$. mediterranei is one of the most promising and versatile PHBV-producing haloarchaeon because of its ability to incorporate $3 \mathrm{HV}$ monomer up to $10 \mathrm{~mol} \%$ from unrelated and cheap carbon sources. This high $3 \mathrm{HV}$ molar fraction is mainly due to the presence of multiple 3HV monomer supplying pathways in Hfx. mediterranei. Yangia sp. CCB-MM3 is one of the very few halophilc bacteria which can naturally produce PHBV. One 3HV monomer supplying pathway has been predicted in Yangia sp. CCB-MM3. Discovery of these pathways provides a novel opportunity to engineer the PHBV synthetic pathway for obtaining PHBV polymers with controlled $3 \mathrm{HV}$ molar fraction.

Propionyl-CoA is an important precursor for $3 \mathrm{HV}$ monomer generation. Hfx. mediterranei simultaneously utilizes four pathways for supplying propionylCoA during PHBV synthesis when glucose is the main carbon source: citramalate/2-oxobutyrate pathway, aspartate/2-oxobutyrate pathway, methylmalonyl-CoA pathway, and 3-hydroxypropionate pathway [99]. Both citramalate/2-oxobutyrate pathway and aspartate/2oxobutyrate pathway transforms 2-oxobutyrate to propionyl-CoA. Citramalate/2-oxobutyrate pathway generates 2-oxobutyrate from acetyl-CoA and pyruvate while aspartate/2-oxobutyrate pathway proceeds by converting oxaloacetate-derived threonine and methionine into 2-oxobutyrate. Finally, 2-oxobutyrate generated from these two pathways is decarboxylated to propionylCoA. Methylmalonyl-CoA pathway converts succinylCoA via (S)-methylmalonyl-CoA to propionyl-CoA.
The fourth pathway, 3-hydroxypropionate pathway, was a novel finding, proposed in haloarchaea for the first time. It converts acetyl-CoA and $\mathrm{CO}_{2}$ via formation of 3-hydroxypropionate to propionyl-CoA. Interestingly, almost $83.6 \%$ of the 3 -HV monomer composition is provided by the citramalate/2-oxobutyrate and 3-hydroxypropionate pathway. Unlike the other two pathways which begin with TCA intermediates, these pathways begin with pyruvate and acetyl-CoA and directly store their excess carbon in PHBV granules. Recently, Williams et al. reported that higher abundance of $A B C$ transporter proteins and enzymes involved in branched chain amino acids (BCAA) synthesis were observed in Hrr. lacusprofundi at low temperatures. Since, degradation of BCAA or its intermediate oxoacid precursor can generate propionyl-CoA, it was hypothesized that PHA accumulation was linked to the demand for BCAA in Hrr. lacusprofundi [38].

Yangia sp. CCB-MM3 accumulates PHBV with 7 mol\% $3 \mathrm{HV}$ from unrelated carbon source [107]. The complete set of genes encoding the enzymes of methylmalonylCoA pathway including methylmalonyl-CoA mutase, methylmalonyl-CoA epimerase, and methylmalonyl-CoA decarboxylase have been predicted in this strain [107]. It can be hypothesized that succinyl-CoA is isomerized to (R)-methylmalonyl-CoA by methylmalonyl-CoA mutase. (R)-methylmalonyl-CoA is converted to its $S$-form by methylmalonyl-CoA epimerase. Finally, $(S)$-methylmalonyl-CoA is decarboxylated to propionyl-CoA by methylmalonyl-CoA decarboxylase. Thus, methylmalony-CoA pathway might supply propionyl-CoA for PHBV synthesis in Yangia sp. CCB-MM3.

\section{Regulation of PHA synthesis}

Formation of uniform sized PHA granules and their distribution is a well-regulated process. Two novel PHA granule associated proteins phasin (PhaP) and GAP12 (PhaR) have been identied involved in the regulation of PHA synthesis in haloarchaea $[117,118]$. The two proteins are located on the PHA granules. Their encoding genes form a cluster of maoC-phaR-phaP-phaE-phaC in several haloarchaeal species, including $H f x$. mediterranei, Har. hispanica, Halomicrobium mukohataei, Har. marismortui, Halorhabdus tiamatea, Htg. turkmenica, Hpg. xanaduensis, and Hqr. Walsbyi [117].

PhaP consists of several conserved amino acids and aspartate/glutamate rich regions in its $\mathrm{C}$-terminal that might be important for their function [117]. PhaR protein consists of an AbrB (antibiotic resistance protein B)-like domain and plays an important role in regulating PHA accumulation and granule formation [118]. The phaP gene was cotranscribed with phaR but had higher abundance probably due to its higher translational 
efficiency or stability. Interestingly, the expression level of phaRP was enhanced in the presence of PHA as the activity of the phaRP promoter decreased by twofolds in the $\triangle p h a E C$ and $\triangle p h a P E C$ mutants of Hfx. mediterranei [121]. However, knocking out of the phaR gene increased the activity of the phaRP promoter by fourfolds in the $\triangle p h a R P E C$ mutant, indicating that PhaR is a negative regulator of the phaRP operon [118]. In the case of PHA accumulation, knockout of phaP gene led to $30-40 \%$ decrease in PHA yield whereas knockout of both phaR and phaP genes resulted in $75-85 \%$ decrease. Surprisingly, complementation of phaR gene in the $\triangle p h a R P$ mutant fully restored PHA synthesis, unlike phaP which could only partly restore the PHA yield. However, knockout of either phaP or phaR led to irregular formation of PHA granules. $\triangle p h a P$ mutant strain consisted of only one large round PHA granule with diameter of approximately $1 \mu \mathrm{m}$ compared to the multiple granules of wild strain. Whereas, $\Delta p h a R$ produced irregular shaped small or medium sized granules. Thus, a proper amount of PhaP protein, which is regulated by PhaR, is critical for the uniform sized PHA granule formation and separation.

Additionally, lysine acetylation is another probable factor regulating PHA synthesis [119]. Lysine acetylation is an important post-translational modification of proteins that plays a crucial regulatory role in different cellular activities. Almost $17.3 \%$ of the total proteins are lysine acetylated in $H f x$. mediterranei [119]. Lysine acetylome of $H f x$. mediterranei revealed that some of the key enzymes of PHA biosynthesis were acetylated including PhaA $\alpha$, $\mathrm{BktB} \alpha$, and PhaE subunits [119]. Deacetylation of PhaE significantly reduced PHA synthesis probably due to inefficient interaction between deacetylated PhaE and PhaC subunit on the PHA granules [120]. Additionally, the PhaP protein was also lysine acetylated [119]. Thus, lysine acetylation plays an important role in PHA biosynthesis and its regulation in $H f x$. mediterranei.

H. bluephagenesis TD01 genome consists of one gene encoding PhaR and three putative phaP genes $[52,116]$. Among the three phaPs, only phaP1 was directly related to the amount and size of PHA granules [116]. However, all the three phaPs were involved in PHB synthesis as their deletion led to low PHB accumulation.

\section{PHA mobilization and degradation}

Under conditions of carbon limitation, the intracellularly accumulated PHA is hydrolyzed by PHA depolymerase and other related enzyems so that it can be utilized by the host for growth and survival. The intracellular PHBV gradually degrades when the PHA-rich cells of $H f x$. mediterranei are transferred into a fresh medium without carbon source [121]. Strikingly, in addition to the five PHA granule associated proteins, two new proteins were observed on the PHA granules in this strain. One protein, identified as the novel intracellular PHA depolymerase PhaZh1, was a palatin-like protein and contained a classical lipase box-like sequence (Gly-Thr-Ser-GlyGly), critical for hydrolytic activity. Although PhaZh1 hydrolyzed PHA granules in vitro, knockout of its encoding gene had no effect on intracellular PHA mobilization. This indicated the presence of alternative PHA degradation pathway in $H f x$. mediterranei. The other protein BdhA (3HB dehydrogenase) was encoded by the gene located upstream of phaZh1 [121]. BdhA converted 3HB monomers generated by PhaZ1 from natural PHA granules into acetoacetate. $H$. bluephagenesis TD01 has three PhaZs among which only PhaZ3 probably is an extracellular depolymerase due to the presence of a signal peptide, while PhaZ1 and PhaZ2 are intracellular depolymerases because they lacked signal peptides [52].

The fifth gene $(m a o C)$ of the cluster maoC-phaR-phaPphaE-phaC in Hfx. mediterranei, redesignated as phaJ, encodes $(R)$-specific enoyl-CoA hydratase [100]. Despite of its organization with other pha genes, this gene has no function in PHA synthesis as PHBV yield was unaffected by its deletion. Instead, when the PHA-rich cells were transferred into fresh medium without carbon source, this protein catalyzed the dehydration of 3-hydroxyacylCoA to enoyl-CoA [100]. Enoyl-CoA is an intermediate of $\beta$-oxidation pathway, implying that PHA accumulated in $H f x$. mediterranei is degraded and mobilized through $\beta$-oxidation pathway. As a confirmation, the expressions of genes encoding 3-hydroxyacyl-CoA dehydrogenase, the key enzyme of $\beta$-oxidation pathway, were clearly upregulated after PHA-rich cells were transferred to fresh medium. Probably, this linkage of PHA degradation to $\beta$-oxidation pathway is a common route in haloarchaea as $96 \%$ of the species possessing PhaJ also contains the full set of genes involved in $\beta$-oxidation pathway.

The series of studies involving bioinformatics analysis and molecular characterization have provided valuable insights into the divisity of PHA metabolism and regulation in haloarchaea and halophilic bacteria [100-121]. Futhermore, the above-mentioned achievements in this secion have also refined the differences between the domains of Bacteria and Archaea.

\section{Strategies for novel PHA synthesis and production improvement}

Although over 150 different monomers have been incorporated into PHA chains under various fermentation conditions, only few are available commercially. Now, the search for PHA with novel monomer composition and mechanical properties is still on. Sometimes, simple cofeeding strategies can synthesize novel and tailored 
PHA. However, most of the times combined efforts of metabolic engineering and synthetic biology are needed. Another challenge limiting PHA commercialization is low efficiency in microbial PHA synthesis. The following section is a summary on the various strategies developed to improve PHA yield and synthesize novel PHA in halophiles.

\section{Halomonas species PHBV synthesis}

H. bluephagenesis TD01 is a promising PHA-producing halophile due to its ability to undergo fermentation under continuous unsterile process without contamination. However, it inherently produces only PHB. Analysis of the PHBV synthesis pathway in $H$. bluephagenesis TD01 revealed that propionic acid is converted into propionyl-CoA, which further enters the methylcitric acid cycle (MCC cycle) and TCA cycle [98]. The key enzyme responsible for driving propionyl-CoA to MCC cycle is 2-methylcitrate synthase encoded by $\operatorname{prp} C$ gene. The knockout strain of $\operatorname{prpC}$ gene, named as TD04, produced PHBV with $12.03 \mathrm{~mol} \%$ of $3 \mathrm{HV}$ when $0.5 \mathrm{~g} / \mathrm{L}$ of propionic acid was co-fed with glucose. In contrast, the wildtype strain, TD01, could incorporate only $0.82 \mathrm{~mol} \%$ of $3 \mathrm{HV}$ under the same condition. Moreover, the conversion efficiency of propionic acid to $3 \mathrm{HV}$ underwent ninefold increase in TD04. The 2-methylcitrate synthase is an important control point for PHBV synthesis in Halomonas TD01 and was further confirmed by complementation of the $\operatorname{prpC}$ gene. Complementation of the $\operatorname{prpC}$ gene in TD04 reverted the 3HV level to that of TD01. Another mutant strain, named as TD08, was further developed by deletion of three phaZ genes along with $\operatorname{prp} C$ gene and subjected to open fermentation process performed in 500-L fermentor for $70 \mathrm{~h}$. The mutant TD08 grew up to $80 \mathrm{~g} / \mathrm{L}$ consisting of $70 \%$ (wt) PHBV containing $8 \mathrm{~mol} \% 3 \mathrm{HV}$ when supplying $0.5 \mathrm{~g} / \mathrm{L}$ of propionic acid and glucose concentration maintained at $20 \mathrm{~g} / \mathrm{L}$ during growth phase. In contrast, this mutant gave 112 g/L CDW consisting of approximately 70\% (wt) PHB when only supplied with glucose.

Despite of higher 3HV molar fraction in PHBV, engineered Halomonas TD04 exhibited poor CDW which led to low PHBV production. In the presence of $1.0 \mathrm{~g} / \mathrm{L}$ propionic acid, TD04 could attain CDW of only $3.69 \mathrm{~g} / \mathrm{L}$ containing 32.42\% (wt) PHBV [98]. In contrast, CDW of TD01 was $9.17 \mathrm{~g} / \mathrm{L}$ containing $78.87 \%$ (wt) PHBV. CRISPRi system consists of a denatured Cas 9 protein and small guide RNA (sgRNA) complex. sgRNA guides the complex to the target DNA sequence and the catalytically dead and mutated denatured Cas9 protein with DNA binding ability binds to the targeted sequence to repress its expression. As $\operatorname{prpC}$ was critical for PHBV synthesis by $H$. bluephagenesis, Tao et al. designed seven sgRNAs (TD-prpC1 to TD-prpC7) targeting different sites of the $\operatorname{prp} C$ gene to give different repressive effects [110]. For instance, $3 \mathrm{HV}$ content was 1.79, 4.78, 5.72, 6.44, 8.16, 11.94 , and $12.15 \mathrm{~mol} \%$ for TD-prpC1 to TD-prpC7, whereas TD01 yielded $0.89 \mathrm{~mol} \% 3 \mathrm{HV}$. The combination of prpC6 and prpC7 inhibition sites further improved the $3 \mathrm{HV}$ content to $12.7 \mathrm{~mol} \%$. CDW and PHBV content of all the strains were maintained within the range of $13-15 \mathrm{~g} / \mathrm{L}$ and $73-80 \%(\mathrm{wt})$, respectively, in the presence of $1.0 \mathrm{~g} / \mathrm{L}$ propionic acid. Thus, CRISPRi system is a promising strategy allowing synthesis of PHBV with varied $3 \mathrm{HV}$ molar fraction, without impairing cell growth.

The requirement of propionic acid as $3 \mathrm{HV}$ precursor added extra cost to the fermentation process. Hence, attempts were further made to produce PHBV directly from unrelated carbon sources. The oxaloacetate generated from phosphoenolpyruvate and the TCA cycle is mostly channelled to propionyl-CoA via threonine synthesis. It was evident that the overexpression of threonine synthesis operon, thr $A C B$, and threonine dehydrogenase encoding gene, ilvA, in TD08 incorporated almost $4 \mathrm{~mol} \% 3 \mathrm{HV}$ in polymer chains using glucose as sole carbon source [111]. Additionally, the engineered strain was able to synthesize PHBV with $4.03-6.12 \mathrm{~mol} \%$ of 3 HV by utilizing sucrose, maltose, fructose, and glycerol [111]. The genome of $E$. coli consists of an operon (scpA-argK$s c p B-s c p C$ ), related to conversion of succinyl-CoA to propionyl-CoA. Methylmalonyl-CoA mutase (ScpA) and methylmalonyl-CoA decarboxylase $(\mathrm{ScpB})$ converts succinyl-CoA to propionyl-CoA, propionyl-CoA/succinylCoA transferase (ScpC) converts propionyl-CoA back to succinyl-CoA and $\operatorname{argK}$ encodes a putative kinase whose exact function is unclear. When $s c p A-\arg K-s c p B$ fragment was cloned and integrated into the chromosome of TD08, resulting a mutant named as TD08AB, PHBV with $7.3 \mathrm{~mol} \% 3 \mathrm{HV}$ was obtained using glucose as sole carbon source [122]. Contrarily, TD08 (pRE112-pMB1scpAB), harbouring the plasmid carrying $s c p A$ and $s c p B$ resulted in lower $\mathrm{CDW}$ but $3 \mathrm{HV}$ content was as high as $25 \mathrm{~mol} \%$. Interestingly, TD08AB showed even better performance in open fermentation process performed in 6-L fermentor compared to TD08 (pRE112-pMB1-scpAB). Both the strains produced PHBV with $11 \mathrm{~mol} \%$ which indicated that the scale-up increased $3 \mathrm{HV}$ molar fraction in TD08AB but got significantly reduced in TD08 (pRE112-pMB1-scpAB). Furthermore, the cell growth was better for TD08AB, implying that chromosomal expression is a much efficient tool for genome engineering for long-lasting fermentation process. In 2019, an efficient engineered strain that could accumulate up to $25 \mathrm{~mol} \% 3 \mathrm{HV}$ was developed using the chromosomal expression system [25]. The authors developed several 
strategies to achieve it. In the first strategy, the TCA cycle was engineered by deleting the genes $s d h E$ and $i c l$ encoding succinate dehydrogenase assembly factor 2 and isocitrate lysase in TD08AB. This redirected more metabolic flux towards $3 \mathrm{HV}$ synthesis and resulted in $78 \%$ increase in $3 \mathrm{HV}$ supplying compared to TD08AB. In the second strategy, a strain named as TY194 was developed by integrating scp $A B$ under the control of a $\mathrm{P}_{\text {porin }}$ promoter into the chromosome of TD1.0 ( $\triangle p r p C)$. Then, $s d h E$ and $i c l$ was deleted, alone or in combination, but the recombinant strains only accumulated PHBV with 3-5 mol\% $3 H V$. In the third strategy, TY194 ( $\Delta s d h E \Delta i c l)$ was grown in the presence of $2 \mathrm{~g} / \mathrm{L}$ sodium gluconate, obtained from starch processing industry along with $30 \mathrm{~g} / \mathrm{L}$ glucose. Sodium gluconate reduced $\mathrm{NADH} / \mathrm{NAD}^{+}$ratio which could accelerate glycolytic flux and TCA cycle. $3 \mathrm{HV}$ content was $18 \mathrm{~mol} \%$ for TY194 ( $\Delta s d h E \Delta i c l)$ whereas it was less than $5 \mathrm{~mol} \%$ in TD08AB and TY194. In the final strategy, $p p c$ encoding phosphoenolpyruvate carboxylase and $v g b$ encoding Vitreoscilla hemoglobin ( $\mathrm{VHb}$ ) under the control of strong $\mathrm{P}_{\text {porin }}$ promoter and eight tandemly connected $v g b$ promoter $\mathrm{P}_{8 \mathrm{vgb}}$, respectively, was integrated into the chromosome of TY194 $(\Delta s d h E)$. The resulting engineered strains generated PHBV with $3 \mathrm{HV}$ content varying from $3-25 \mathrm{~mol} \%$ when grown on glucose with/without gluconate. The most efficient strain was H. bluephagenesis TY194 ( $\Delta s d h E, \mathrm{G7}:: \mathrm{P}_{\text {porin }}$-ppc) which produced $6.3 \mathrm{~g} / \mathrm{L}$ CDW containing 65\% (wt) PHBV with $25 \mathrm{~mol} \% 3 \mathrm{HV}$ from glucose and gluconate. The engineered strains of $H$. bluephagenesis TD01 are enlisted in Table 6.

Halomonas sp. SF2003 was proved as a good candidate for tailor-made PHBV synthesis as it was capable of producing PHBV with tunable proportions of $3 \mathrm{HV}$ monomer when various quantities of valeric acid was cofed with glucose [123]. This strain successfully incorporated 15, 23, 27 and $35 \mathrm{~mol} \%$ of $3 \mathrm{HV}$ monomer into $\mathrm{PHB}$ chains and thus generated PHBV polymers with greatly modified morphology and mechanical properties.

\section{Synthesis of PHA containing 4-hydroxybutyrate (4HB) monomer}

Compared to $\mathrm{PHB}$ and PHBV, 4HB-containing PHA has a wide variety of mechanical and physical properties. Depending on the $4 \mathrm{HB}$ content, polymer property changes from crystallinity to elasticity [124]. 4HB incorporation not only widens the application potentials but also improves the biodegradability of PHA [125]. Thus, synthesis of PHA with higher 4HB molar fraction is an active research area. Most microbes require $4 \mathrm{HB}$ precursors including $\gamma$-butyrolactone (GBL) and 1,4-butanediol to generate $4 \mathrm{HB}$ monomer. Unfortunately, Halomonas cannot synthesize $4 \mathrm{HB}$ monomer even from these precursors. H. bluephagenesis TD01 lacks 4HB-CoA transferase gene, orf $Z$, which converts $4 \mathrm{HB}$ to $4 \mathrm{HB}-\mathrm{CoA}$ [126]. Interestingly, when orfZ of Clostridium kluyveri was integrated into the chromosome of $H$. bluephagenesis TD01, the recombinant strain TD40 produced $7.2 \mathrm{~g} / \mathrm{L}$ CDW containing 62.6\% (wt) P3HB4HB with 9 mol\% $4 \mathrm{HB}$ on $20 \mathrm{~g} / \mathrm{L}$ glucose and $5 \mathrm{~g} / \mathrm{L} \mathrm{GBL}$ in shake flask experiments after $48 \mathrm{~h}$. When cultivated in 1-L and 7-L fermentor under non-sterile and open conditions, the strain produced $65 \mathrm{~g} / \mathrm{L}$ CDW containing 53\% (wt) $\mathrm{P}(3 \mathrm{HB}-$ co-11 mol\% 4HB) and $72 \mathrm{~g} / \mathrm{L}$ CDW containing $63 \%(\mathrm{wt})$ $\mathrm{P}(3 \mathrm{HB}-c o-12.3 \mathrm{~mol} \% 4 \mathrm{HB})$ after $48 \mathrm{~h}$, respectively. When scaled up to 1000-L fermentor vessel, $82.6 \mathrm{~g} / \mathrm{L}$ CDW containing $61 \%(\mathrm{wt}) \mathrm{P}(3 \mathrm{HB}-\mathrm{co}-16 \mathrm{~mol} \% \mathrm{4HB})$ was achieved after $48 \mathrm{~h}$. The produced P3HB4HB was a block copolymer and thus exhibited good elasticity with an elongation at break of $1022 \pm 43 \%$. Furthermore, the recombinant strain efficiently gave $81.4 \mathrm{~g} / \mathrm{L}$ CDW containing $73.8 \%$ (wt) $\mathrm{P}$ (3HB-co-11.6 mol\% 4HB) in 7.5-L fermentor when waste corn steep liquor (CSL) along with glucose and GBL was used as substrates [124]. Further scale up to 5000-L fermentor generated 99.6 g/L CDW containing 60.4\% (wt) $\mathrm{P}(3 \mathrm{HB}-\mathrm{co}-13.5 \mathrm{~mol} \%$ 4HB). The reduction in P3HB4HB content was attributed to the usage of liquid CSL instead of dried CSL powder used in 7.5-L fermentor. CSL can supply rich nutrients including amino acids and vitamins and thus, can reduce the consumption of expensive raw materials. Interestingly, replacement of glucose with waste gluconate, produced $68.1 \mathrm{~g} / \mathrm{L} \mathrm{CDW}$ containing $70.6 \%(\mathrm{wt}) \mathrm{P}(3 \mathrm{HB}-\mathrm{co}-12.4 \mathrm{~mol} \% 4 \mathrm{HB})$ in $7.5-\mathrm{L}$ fermentor. Thus, use of CSL and waste gluconate is an effective approach towards cost reduction of $\mathrm{P} 3 \mathrm{HB} 4 \mathrm{HB}$ production.

However, one of the shortcomings for TD40 is the presence of only one copy of $\mathrm{P}_{\text {tac }}$-orf $Z$, which is insufficient to meet the industrial demands. Therefore, promoter engineering was employed to enhance the orf $Z$ gene expression. The core region from -35 box to the transcription initiation site of $\mathrm{P}_{\text {porin }}$, was modified to generate promoters with a wide range of transcriptional strengths [127]. Recombinant strains with moderate and strong promoter strength, named as TDH4 and TDH5, respectively, gave better performances. For instance, in 7-L fermentor, TDH4 consumed 17\% less GBL compared to TD40 but the $4 \mathrm{HB}$ incorporated was the same with TD40 (11 mol\%) [126]. Whereas, TDH5 consumed the same amount of GBL as that of TD40 but $4 \mathrm{HB}$ content was $40 \%$ higher than TD40 indicating that TDH5 had a higher substrate to $4 \mathrm{HB}$ conversion rate [127]. Thus, promoter engineering efficiently increased the $4 \mathrm{HB}$ content of P3HB4HB in the engineered strains. Subsequently, it was observed that TDH4 cells normally contained 4 to 12 granules of P3HB4HB. When phaP1 was deleted, TDH4 


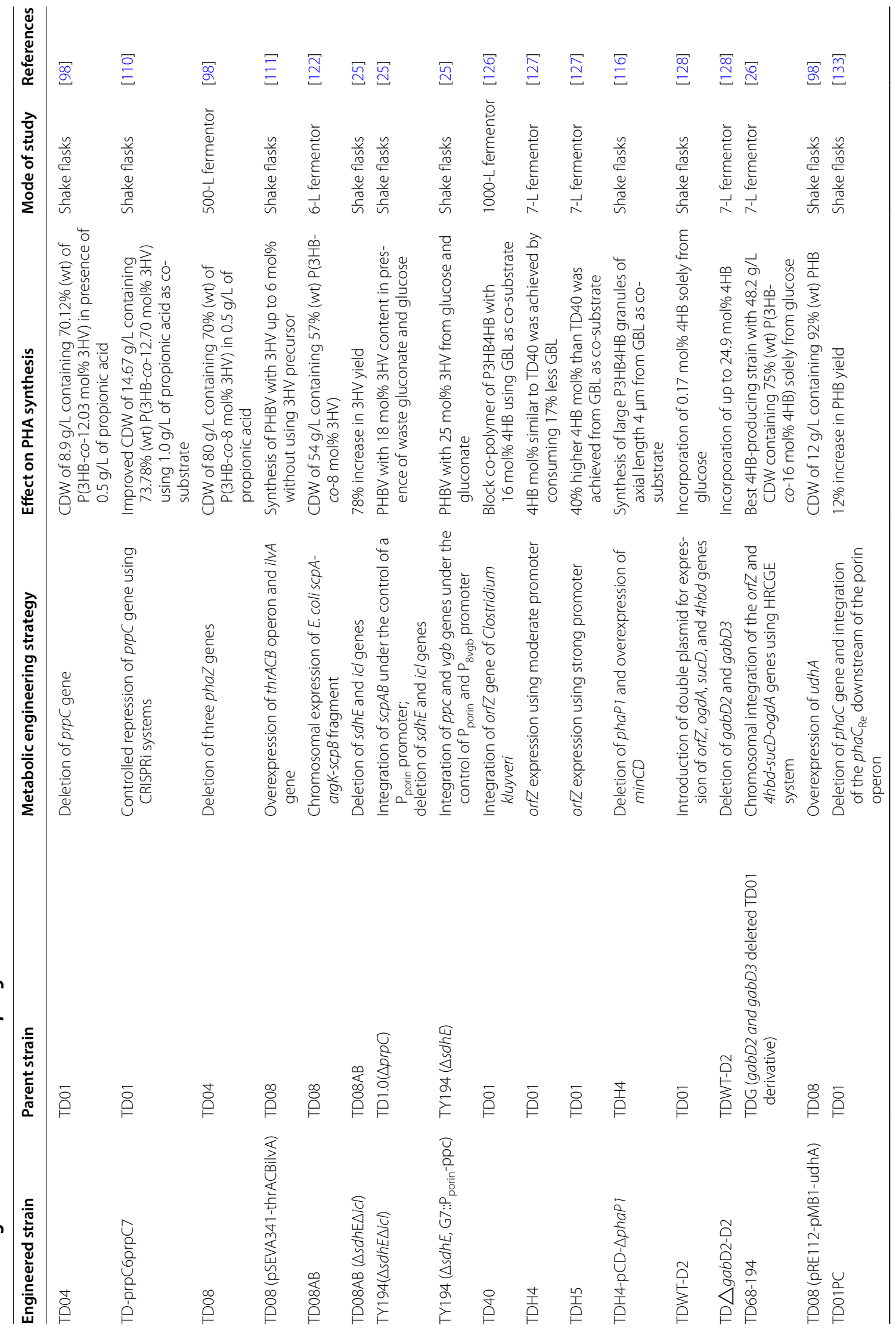




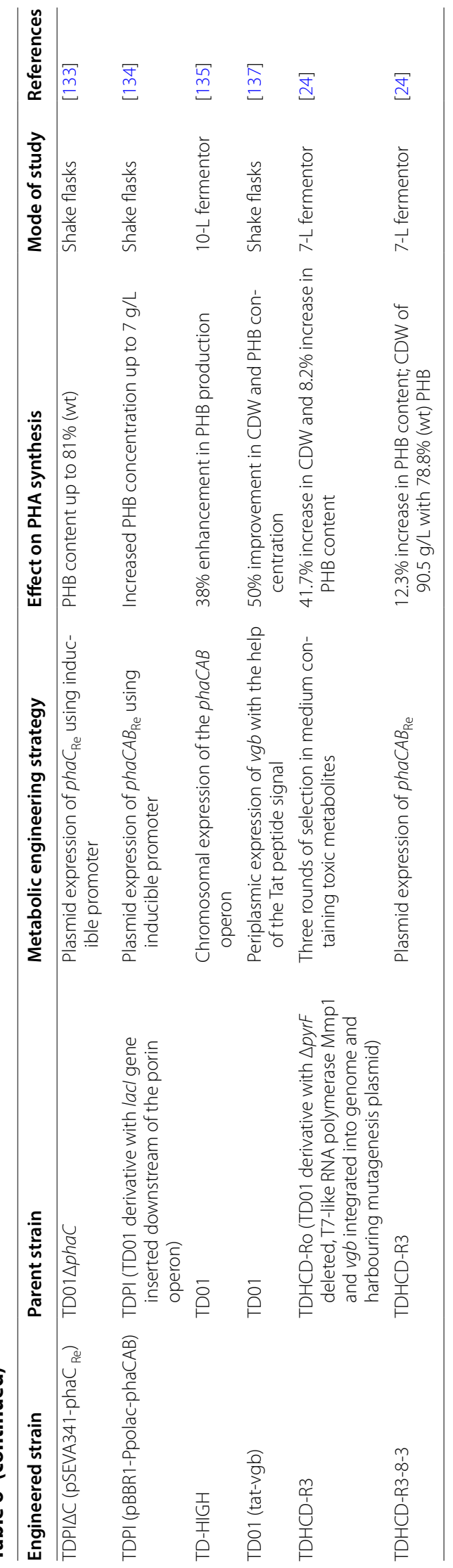


produced only one single large granule. Further, $\min C D$ overexpression in TDH4- $\Delta$ phaP1 increased 4HB mol\% by $14 \%$ and the resultant $\mathrm{P} 3 \mathrm{HB} 4 \mathrm{HB}$ granule had an axial length of $4 \mu \mathrm{m}$ [116]. Unlike TDH4 cells, recombinant TDH4-pCD- $\Delta$ phaP1 cells containing larger P3HB4HB granules could be easily precipitated at a centrifugation force of $3000 \times g$ for $5 \mathrm{~min}$.

Despite the production of P3HB4HB with higher 4HB content, use of GBL is still a drawback as it incurs additional production cost. Hence, further pathway engineering was done to produce P3HB4HB solely from glucose. P3HB4HB synthesis pathway from glucose involves 2-oxo-glutarate dehydrogenase, encoded by $o g d A$, and succinate semialdehyde dehydrogenase, encoded by $s u c D$, which directs the synthesis of succinate semialdehyde (SSA) from 2-oxoglutarate and succinyl-CoA in the TCA cycle, respectively [128]. SSA is converted to $4 \mathrm{HB}$ by 4-hydroxybutyrate dehydrogenase encoded by $4 h b d$ and further to $4 \mathrm{HB}-\mathrm{CoA}$ by $4 \mathrm{HB}-\mathrm{CoA}$ transferase encoded by orfZ. Finally, 3HB-CoA and $4 \mathrm{HB}-\mathrm{CoA}$ are polymerized to produce $\mathrm{P} 3 \mathrm{HB} 4 \mathrm{HB}$ by $\mathrm{PHA}$ synthase. Thus, one plasmid harbouring orf $Z$ gene and another plasmid harbouring $\operatorname{ogdA}, s u c D$, and $4 h b d$ genes driven by a strong promoter $\mathrm{P}_{\text {porin }}$ were constructed [128]. This double plasmid system, termed as D2 system, was introduced into TD01. The engineered strain, named as TDWT-D2, produced P3HB4HB with only $0.17 \mathrm{~mol} \% 4 \mathrm{HB}$ from glucose. Thus, efforts were made to further enhance the flux of $4 \mathrm{HB}$ synthesis. The intracellular accumulation of SSA, which is the precursor of $4 \mathrm{HB}$, is toxic to cell, hence, most bacteria possesses SSA degradation pathway. Succinate semialdehyde dehydrogenase (SSADH) converts SSA into succinate to minimize the toxicity. TD01 possesses five orthologs of succinate semialdehyde dehydrogenase (SSADH) encoding gene gabD (gabD1-gabD5). Interestingly, deletion of gabD2 and gabD3 in TDWT-D2, yielding TD $\triangle g a b \mathrm{D} 2-\mathrm{D} 2$ increased $4 \mathrm{HB}$ molar fraction to $4.06 \mathrm{~mol} \%$. Fermentation conducted in 1-L bioreactor produced $\mathrm{P}(3 \mathrm{HB}-\mathrm{co}-11.0 \mathrm{~mol} \%$ 4HB). Furthermore, in a 7-L bioreactor under fed-batch conditions, $26.3 \mathrm{~g} / \mathrm{L}$ CDW containing 60.5\% (wt) $\mathrm{P}(3 \mathrm{HB}-c o-17.0 \mathrm{~mol} \%$ 4HB) was obtained. Additionally, it was possible to tune $4 \mathrm{HB}$ molar fraction from 13.4 to $24.9 \%$ by varying the residual glucose concentration from 5 to $20 \mathrm{~g} / \mathrm{L}$. Thus, this is an explicit design that two interrelated pathways jointly work to synthesize P3HB4HB directly from glucose.

Very recently, fine tuning for P3HB4HB synthesis has been possible through high-resolution control of gene expressions (HRCGE) system. Gene deletions and overexpression usually lead to instability of cellular system. For instance, high accumulation of $4 \mathrm{HB}$ and SSA are toxic to the cell growth, but they are important intermediates for 4HB synthesis pathway. Thus, HRCGE system provides an accurate, controlled and optimized transcriptional level of gene expression by employing two inducible systems with high- and low-dynamic ranges. By using HRCGE system, the expression of orf $\mathrm{Z}$ and $4 \mathrm{hbd}$ sucD-ogdA was fine-tuned by optimizing IPTG induction concentration and varying promoter combinations [26]. This fine-tuned $4 \mathrm{HB}$ pathway when integrated into the chromosome of TDG (gabD2 and gabD3 deleted TD01 derivative), generated the recombinant strain TD68-194. Compared to TD $\triangle g a b \mathrm{D} 2-\mathrm{D} 2$ [128], TD68-194 displayed improved $\mathrm{P} 3 \mathrm{HB} 4 \mathrm{HB}$ synthesis producing $48.2 \mathrm{~g} / \mathrm{L} \mathrm{CDW}$ containing $75 \%(w t) \mathrm{P}(3 \mathrm{HB}-c o-16 \mathrm{~mol} \% \mathrm{HHB})$ from glucose in 7-L fermentor [26]. Till now, this is the best strain reported to produce $\mathrm{P} 3 \mathrm{HB} 4 \mathrm{HB}$ containing higher that $15 \mathrm{~mol} \%$ 4HB from glucose as the sole carbon source. The engineered strains derived from $H$. bluephagenesis TD01 are enlisted in Table 6.

\section{Enhancement of PHA synthesis}

The reduction of acetoacetyl-CoA to 3-hydroxybutyrate-CoA by $\mathrm{PhaB}$ requires $\mathrm{NAD}(\mathrm{P})(\mathrm{H})$ as cofactor. $H$. bluephagenesis TD01 possesses NADH-dependent PhaB, which means it can accumulate PHA from acetyl-CoA by using NADH instead of NADPH as cofactor. Oxygen limitation significantly increases $\mathrm{NADH} / \mathrm{NAD}^{+}$ratio which indicates that the surplus amount of NADH produced during glycolysis and pyruvate metabolism can be used for PHA synthesis in H. bluephagenesis TD01 [115]. The well-designed study by Ling et al., proved that NADH/ $\mathrm{NAD}^{+}$ratio is an important parameter to channelize more acetyl-CoA towards PHA synthesis [115]. NADH/ $\mathrm{NAD}^{+}$ratio was more than 1.5 when $H$. bluephagenesis TD01 grows in LB medium and is higher than many other microorganisms. The genome of TD01 has the genes encoding acetate utilization proteins, including acetyl-CoA synthetase, acetate kinase, and phosphate acetyltransferase. These enzymes are expected to convert acetate to acetyl-CoA and thus generate $3 \mathrm{HB}-\mathrm{CoA}$ for PHA synthesis under conditions of oxygen limitation. Co-feeding $6 \mathrm{~g} / \mathrm{L}$ acetate with $30 \mathrm{~g} / \mathrm{L}$ glucose generated more acetyl-CoA and enhanced PHB concentration from 8.06 to $10.4 \mathrm{~g} / \mathrm{L}$ in TD01 [115]. Furthermore, manipulation of the NADH utilization pathway was another possible way to engineer the $\mathrm{NADH} / \mathrm{NAD}^{+}$ratio. Bioinformatics analysis revealed two sets of electron transfer flavoproteins (ETF-X) and one ETF-oxidoreduacase (ETF-QO) involved in the NADH-dependent respiratory chain of TD01 [115]. Both ETFs are composed of two subunits, $\alpha$ and $\beta$, in a same operon. ETF-X plays an electron shuttling role by transferring the reducing equivalents to the respiratory chain. Interestingly, in the presence of $3 \mathrm{~g} / \mathrm{L}$ acetate, deletion of the etf- $x-\beta$ gene enabled the mutant to accumulate larger sized PHB granule, 
yielding 94\% PHA content of the CDW, without affecting cell growth. Besides $3 \mathrm{HB}-\mathrm{CoA}$ monomer generation, acetate co-feeding positively affected the $3 \mathrm{HV}-\mathrm{CoA}$ and $4 \mathrm{HB}-\mathrm{CoA}$ monomers synthesis. The $3 \mathrm{HV}$ and $4 \mathrm{HB}$ monomers are derived from TCA and glyoxylate cycles. Thus, modulating NADH/NAD ${ }^{+}$ratio will control the acetylCoA flux to these cycles. The $3 \mathrm{HV}$ content of PHBV in the engineered TD08AB increased from 4.2 to $8.4 \mathrm{~mol} \%$ when $2 \mathrm{~g} / \mathrm{L}$ of acetate was co-fed with glucose. Whereas, $4 \mathrm{HB}$ content in the engineered TD $\Delta g a b \mathrm{D} 2-\mathrm{D} 2$ increased from 7.9 to $12.0 \mathrm{~mol} \%$ by cofeeding $4 \mathrm{~g} / \mathrm{L}$ of acetate with glucose. Engineering the redox potential under oxygen limitation is an energy saving strategy that can reduce scale up complexities.

PntAB and UdhA are the two isoforms of pyridine nucleotide transhydrogenase that catalyzes the reduction of $\mathrm{NADP}^{+}$and reoxidation of $\mathrm{NADPH}$, respectively. However, it is speculated that these enzymes have important roles in maintaining the NADPH availability in the cell [129]. For instance, when there are circumstances of significant NADPH drain (such as during PHA synthesis), $u d h A$ overexpression reduces the metabolic burden of the cell by favouring NADPH production [130]. Overexpression of $u d h A$ has been found to be an effective strategy to increase product formation in various organisms including E. coli and Bacillus substilis [131, 132]. Interestingly, $u d h A$ overexpression in strain TD08 increased the PHB accumulation from 87 to $92 \%$ (wt) and glucose conversion to PHB from 30 to 42\% [98]. Porin, a major outer membrane protein, is one of the most strongly expressed proteins in $H$. bluephagenesis. Integration of the phaC gene from $R$. eutropha into the chromosome of phaC-deletion strain of TD01, just downstream of the porin operon (recombinant strain named TD01PC), produced $9.16 \mathrm{~g} / \mathrm{L}$ PHB. This yield was $12 \%$ higher than that of TD01, inferring that chromosomal expression driven by a strong promoter is a promising platform to obtain enhanced product yield [133]. Subsequently, the core promoter region of porin was identified and the lacI gene was integrated downstream of porin ORF, generating the strain TDPI $[133,134]$. An inducible promoter was then produced by inserting the lac operator downstream of $P_{\text {porin }}$ to obtain tuned gene expression. Transformation of the plasmid harbouring phaC gene from $R$. eutropha under the control of this inducible promoter into TDPI $\Delta$ phaC synthesized PHB with content varying from 2 to $81 \%$ (wt) depending on the IPTG (inducer) concentration [133]. Similarly, inducible expression of phaCAB operon from $R$. eutropha in TDPI yielded PHB with concentrations from 2 to $7 \mathrm{~g} / \mathrm{L}$ [134]. Thus, inducible expression system effectively promoted PHB synthesis in H. bluephagenesis. A phage derived novel T7-like MmP1 RNA polymerase-based system was further developed which enabled efficient chromosomal expression of phaCAB operon. Chromosomal expression of the phaCAB operon in TD01 generated a new recombinant strain named TD-HIGH [135]. In a 10-L fermentor, TDHIGH generated $69 \mathrm{~g} / \mathrm{L}$ PHB compared to $50 \mathrm{~g} / \mathrm{L}$ PHB produced by TD01.

Several factors including cell size, PHA granule size, oxygen availability to cell, and cell density are directly correlated to high efficiency of PHA production. Cell size is an important parameter that affects PHA granule size. When TD08 mutant was transformed with an inducible expression vector harbouring a cell division inhibitor gene, $\min C D$, yielded $\mathrm{CDW}$ of $8.33 \mathrm{~g} / \mathrm{L}$ containing $77.16 \%$ (wt) PHBV [111]. Addition of IPTG at the stationary phase of cell growth induced overexpression of the $\min C D$ gene and cell elongation which resulted in a CDW of $8.46 \mathrm{~g} / \mathrm{L}$ containing $82.04 \%$ (wt) PHB. Highly efficient expression of $\min C D$ using the T7-like MmP1 system further led to 100-folds increase in cell length [135]. Increase in cell size not only enhanced PHA accumulation but also produced larger PHA granules which were easy to precipitate and recover during downstream processing. Shen et al. initially tried to increase PHA granule size by deleting phaP genes [116]. The three putative phaP genes, phaP1, phaP2, and phaP3, in TD01 were deleted to generate single, double, and triple knockouts. Among them, phaP1 was majorly related to the granule size as its deletion resulted in double sized single granule formation whereas its complementation restored the multiple small sized granule formation. However, the cell sizes of the mutants were not significantly changed compared to TD01. Interestingly, phaP1 deletion in TD01 with MinCD overexpression using T7-like MmP1, whose granule diameter was otherwise around $1 \mu \mathrm{m}$, produced super large PHB granules with an axial length of $10 \mu \mathrm{m}$. Thus, PHA granule sizes depended on the cell size. An enlarged and elongated cell will yield large and elongated PHA granules.

Oxygen availability to the cell during fermentation is another parameter that strongly affects cellular metabolism. Expression of $v g b$ gene in engineered strains has allowed improvements of bioproduct formation by enhancing oxygen availability [136]. When $v g b$ along with phaCAB under the control of $\mathrm{P}_{8 v g b}$ promoter was heterologously expressed in TD01, 75\% (wt) PHB was achieved compared to $36.6 \%$ (wt) PHB of the control strain containing empty plasmid under low-oxygen conditions [137]. To further enhance the oxygen uptake, a chromosomal expression system of TD01 for periplasmic expression of $v g b$ with the help of the twin-arginine translocation (Tat) peptide signal was constructed. Periplasmic $v g b$ expression resulted in 50\% improvement of CDW and PHB concentration. This strategy enhanced 
ATP and NADH/NAD ${ }^{+}$levels in H. bluephagenesis and improved its cell density and PHB synthesis.

Next, a high-cell-density strain was obtained by genome-wide random mutagenesis and selection stress method to enhance PHB synthesis [24]. Firstly, an engineered strain was obtained by pyrF gene knockout and T7-like RNA polymerase Mmp1 gene and $v g b$ gene integration into the genome of TD01. The resulting strain was further transformed by an expression plasmid containing pyrF in the backbone, to ensure long term selection process, and an error-prone DNA polymerase III $\varepsilon$ subunit from TD01. The finally obtained strain, named as TDHCD-Ro, was allowed to grow for a few generations in selective medium containing toxic metabolites including acetate, formate, lactate, and ethanol. After 3 selection rounds, the best mutant strain was selected by determining its CDW and PHA content. The finally obtained mutant, TDHCD-R3, showed $41.7 \%$ increase in CDW and $8.2 \%$ increase in PHB content compared to TDHCD-Ro. Construction of this high-cell-density strain was based on the assumption that the strain which survived in the presence of toxic metabolites would have high cell density. Thus, the recombinant strain TDHCDR3 was used to give further enhanced PHB content. The plasmid harbouring $R$. eutropha phaCAB operon with suitable promoter and ribosome binding site (RBS) sequence was expressed in TDHCD-R3. The resulting strain TDHCD-R3-8-3 showed a 12.3\% increase in PHB content compared to TDHCD-R3. In a 7-L fermentor, TDHCD-R3-8-3 attained 90.5 g/L CDW with $78.8 \%$ (wt) PHB content while TD01 grew up to $80.6 \mathrm{~g} / \mathrm{L}$ CDW with 69.4\% (wt) PHB content. Interestingly, for a same cultivation time, glucose consumption of TD01 was $253.5 \mathrm{~g}$ more than TDHCD-R3-8-3, indicating a higher conversion efficiency of the latter strain.

Among Halomonas species, H. campaniensis LS21 is another promising species that can accumulate PHB under open and unsterile fermentation conditions. To further improve its production efficiency, cell morphology related genes $m r e B$ and $f t s Z$ were deleted [138]. Since they are essential genes, a temperature-responsible plasmid system was developed to compensate the expression of $m r e B$ or fts $Z$ in the disrupted mutants. The plasmids replicated at $30{ }^{\circ} \mathrm{C}$ so that the mutants attained certain cell density, and then at $37{ }^{\circ} \mathrm{C}$ the plasmids failed to replicate and were eliminated resulting in controlled cell expansion or elongation. In an unsterile 7.5-L bioreactor, the wild type grew up to $27 \mathrm{~g} / \mathrm{L}$ CDW containing $30 \%$ (wt) PHB, whereas both $\triangle m r e B$ mutant and $\Delta f t s Z$ mutant grew up to $34 \mathrm{~g} / \mathrm{L}$ containing $51 \%$ and $60 \%$ (wt) PHB, respectively. Thus, controlling cell morphology efficiently enhanced PHB accumulation in H. campaniensis LS21. Furthermore, a self-flocculating $H$. campaniensis strain LSKO was obtained by knocking out a nonessential etf operon encoding the $\alpha$ and $\beta$ subunits of an electron transfer flavoprotein [139]. LSKO accumulated up to $45 \%$ (wt) PHB. RBS-optimized phaCAB operon from C. necator under the control of $\mathrm{P}_{\text {porin }}$ was transformed to LSKO to get another strain named LSKO-H36-6. LSKO-H36-6 accumulated $85 \%$ (wt) PHB and granules occupied the entire intracellular space. This was also an innovative approach to reduce energy consumption and wastewater generation as the flocculating cells could precipitate without the need of centrifugation and the fermentation supernatant could be efficiently reused in the next cycle.

\section{Haloarchaea}

Among Haloarchaea, $H f x$. mediterranei is a potential cell factory for PHA synthesis. One of the most important advantages of $H f x$. mediterranei is its ability to produce PHBV directly from cheap unrelated carbon source. Moreover, haloarchaea-produced PHBV exhibits distinctive features like lower melting point, lower polydiseperse index, and better hemocompatibility performance compared to bacteria-produced PHBV $[4,140]$. The following section will summarize the efforts made to develop $H f x$. mediterranei as one of the most successful haloarchaea for PHA synthesis.

\section{High-level PHBV synthesis}

EPS synthesized by $H f x$. mediterranei gives it a slimy appearance which helps them to aggregate during extreme conditions. However, EPS synthesis presents several disadvantages to PHA synthesis. First, the secreted EPS increases viscosity of the medium which decreases dissolved oxygen. Second, viscosity increases foaming and thus addition of anti-foaming agent is needed. Third, the carbon source gets divided between EPS and PHA synthesis pathways. In total, all these factors reduce PHA yield, increase fermentation cost, and make PHA recovery difficult. Whole genome sequencing of $H f x$. mediterranei identified the gene cluster involved in EPS synthesis [141]. Knocking out of the gene cluster abolished EPS synthesis and generated a strain named ES1. Interestingly, PHBV production for ES1 was 20\% higher than the wild type and the viscosity of the culture significantly reduced. Moreover, sugar consumption rate and requirement of anti-foaming agent decreased which can reduce the fermentation cost. Thus, ES1 is a highly efficient and promising platform for synthesis of novel PHA. Very recently, another high-yielding ES1 derived strain was serendipitously developed while investigating the phosphoenolpyruvate (PEP)/pyruvate 
interconversion of $H f x$. mediterranei [142]. Surprisingly, deletion of a phosphoenolpyruvate synthetase-like (ppslike) gene accumulated more intracellular PHBV granules and also significantly increased the PHBV content by $70.46 \%$ in shake flask fermentation. Preliminary results explained that pps-like gene knockout upregulated the genes responsible for glucose transportation and PHBV monomer generation. Moreover, the pps-like gene knockout significantly upregulated the PHA synthesis and regulation gene cluster. Their high expression level probably enhanced PHBV accumulation in Hfx. mediterranei.

\section{Synthesis of PHBV with higher 3HV contents}

Han et al. evaluated the effect of valerate supplementation on PHBV synthesis by ES1 and obtained tailor-made random PHBV (R-PHBV) and higher-order copolymers (O-PHBV) [4]. Co-feeding of valerate along with glucose yielded PHBV with $3 \mathrm{HV}$ molar fraction ranging from 9-57 mol\%. Compared to the random arrangement of $3 \mathrm{HB}$ and $3 \mathrm{HV}$ in R-PHBV, O-PHBV consisted of block segments of PHB and PHV and random segments of PHBV. The blocky segments of O-PHBV enhanced its crystallinity and Young's modulus. Additionally, O-PHBV copolymer displayed a novel foveolar clusterlike surface morphology with high surface roughness and high hydrophobicity. Most interestingly, O-PHBV exhibited 3.5 times higher platelet adhesion and 5 times shorter coagulation time than R-PHBV. Thus, synthesis of O-PHBV with excellent hemostatic property is a novel strategy that can provide more biopolymers with great potential in biomedical fields. Furthermore, as $3 \mathrm{HV}$ content increased, the PHBV copolymers became more elastic, with elongation at break ranging from 5 to $430 \%$. These polymers have extremely low endotoxin concentrations due to the structure of archaea cell envelopes, and avoid acute inflammatory responses. Also, they exhibit diversified ranges of biodegradation behaviour when implanted in the rabbit dorsal subcutis [5]. This implied that the novel PHA produced by $H f x$. mediterranei has immense potentials in biomedical applications. Feeding of VFA as sole carbon source can produce PHBV with controlled composition in Hfx. mediterranei [143]. The carbon number of the VFA greatly influenced the monomer composition as carbon-even generated $3 \mathrm{HB}$ rich polymer whereas carbon-odd produced $3 \mathrm{HV}$ rich polymer. Mixtures of butanoic acid and pentanoic acid synthesised bespoke random, block, and blend PHBV with $3 \mathrm{HV}$ content varying from 1 to $100 \mathrm{~mol} \%$ depending on the pentanoic acid percent in the mixture. PHBV with more than $50 \mathrm{~mol} \% 3 \mathrm{HV}$ exhibited lower melting temperature and a wide of range of processing temperature. Compared to the blend PHBV, block and random PHBV exhibited desirable thermal stability. Thus, VFA feeding is an effective strategy to obtain higher $3 \mathrm{HV}$ content in $H f x$. mediterranei.

\section{Synthesis of PHA containing $4 \mathrm{HB}$ monomer}

$H f x$. mediterranei has been less investigated for the synthesis of PHA containing 4HB monomer. However, the most interesting fact revealed from the studies of Koller et al. is that Hfx. mediterranei can synthesis PHBV4HB when GBL was supplied along with valerate and whey sugars [23]. Hfx. mediterranei accumulated $87.5 \%$ (wt) of $\mathrm{P}(3 \mathrm{HB}-\mathrm{co}-21.8 \mathrm{~mol} \% 3 \mathrm{HV}-\mathrm{co}-5.1 \mathrm{~mol} \% 4 \mathrm{HB})$ at a concentration of $14.7 \mathrm{~g} / \mathrm{L}$ in a 10-L bioreactor [23]. Similarly, co-feeding of GBL with crude glycerol obtained from biodiesel industry yielded $68.5 \%$ (wt) P(3HB-co-10 mol\% $3 \mathrm{HV}-\mathrm{co}-5 \mathrm{~mol} \% 4 \mathrm{HB}$ ) at a final concentration of $11.1 \mathrm{~g} / \mathrm{L}$ [68]. These findings inferred that $4 \mathrm{HB}$ monomer supplying pathway from GBL is present in $H f x$. mediterranei. However, since the $4 \mathrm{HB}$ content is relatively low, further genetic engineering $H f x$. mediterranei to enhance $4 \mathrm{HB}$ supplying is an encouraging research field.

\section{Conclusion and future perspectives}

Extensive plastic usage is a global threat to our environment which needs to be addressed with concerted effort. Microbial synthesis of bioplastic PHA and its application is an attractive solution to avert this problem. Compared to other extremophiles, halophiles have been well explored in terms of their biotechnological process in PHA synthesis. They have already been considered as a promising cell factory for PHA synthesis due to their inherent advantages. In this review paper, we have elaborated four major aspects of PHA research: mining of PHA-accumulating halophiles, strategies to reduce the cost of PHA synthesis, PHA metabolism and its regulation in halophiles, and finally, metabolic engineering of halophiles for enhancing PHA production and novel PHA synthesis. Although PHB is more commercialized, enhanced synthesis of PHBV with varied 3HV content has been materialized with advanced metabolic engineering tools and approaches. Tailor-made PHBV synthesis with desired properties has already been accomplished. Furthermore, 4HB monomer synthesis and incorporation into PHA chains by halophile is a milestone in this field.

Dissection of PHA metabolic pathways and its regulation in halophiles is an important avenue in biotechnology. The genetic manipulation and pathway engineering have provided various alternative routes to enhance monomer flux for enhanced scl-PHA synthesis. All the extensive research work carried out in halophiles can speed up their metabolic engineering to realize PHA commercial production at low cost. Moreover, availability of the detailed genetic information on various Halomonas 
species and haloarchaeal species shall definitely facilitate high PHA production from more species. Synthesis of novel PHA is a highly demanding research area as each type of newly synthesized polymer shall exhibit unique property for application which will elevate the status of bioplastics in near future. The heterologous construction of $4 \mathrm{HB}$ pathway in $H$. bluephagenesis is not only an excellent approach to generate $4 \mathrm{HB}$ monomer but also it provides research directives for $4 \mathrm{HB}$ synthesis in more and more halophilic strains. Continued efforts and further investigation with the metabolic engineering tools and strategies are needed to achieve tailor-made $4 \mathrm{HB}$ containing PHA.

\begin{abstract}
Abbreviations
PHA: Polyhydroxyalkanoates; CDW: Cell dry weight; 3HB: 3-Hydroxybutyrate; PHB: Polyhydroxybutyrate; 3HV: 3-Hydroxyvalerate; PHBV: Poly(3-hydroxybutyrate-co-3-hydroxyvalerate); 4HB: 4-Hydroxybutyrate; P3HB4HB: Poly(3hydroxybutyrate-co-4-hydroxybutyrate); PHBV4HB: Poly(3-hydroxybutyrate-co3-hydroxyvalerate-co-4-hydroxybutyrate); VFA: Volatile fatty acids; SDCLA: Seaweed derived crude levulinic acid; C/N: Carbon/nitrogen; EPS: Extracellular polymeric substance; SSF: Simultaneous saccharification and fermentation; ALR: Air-lift reactors; FC: Flow cytometry; BCAA: Branched chain amino acids; GBL: $\gamma$-Butyrolactone; HRCGE: High-resolution control of gene expressions; PPS-like: Phosphoenolpyruvate synthetase-like.
\end{abstract}

\section{Authors' contributions}

$\mathrm{RM}, \mathrm{JH}$ and TX wrote the manuscript. HX gave valuable suggestions. All authors read and approved the final manuscript.

\section{Funding}

This work was supported by the National Key Research and Development Program (No. 2018YFA0900200 to JH), the National Natural Science Foundation of China (No. 31970031 to JH and No. 91751201 to HX) and CAS-TWAS President's Fellowship (to RM).

\section{Availability of data and materials}

Not applicable.

\section{Ethics approval and consent to participate}

Not applicable.

\section{Consent for publication}

Not applicable.

\section{Competing interests}

The authors declare that they have no competing interests.

\section{Author details}

${ }_{1}^{1}$ State Key Laboratory of Microbial Resources, Institute of Microbiology, Chinese Academy of Sciences, Beijing 100101, People's Republic of China. ${ }^{2}$ International College, University of Chinese Academy of Sciences, Beijing 100049, People's Republic of China. ${ }^{3}$ College of Life Science, University of Chinese Academy of Sciences, Beijing 100049, People's Republic of China.

Received: 19 January 2020 Accepted: 26 March 2020

Published online: 07 April 2020

\section{References}

1. Chae Y, An YJ. Current research trends on plastic pollution and ecological impacts on the soil ecosystem: a review. Environ Pollut. 2018:240:387-95.
2. Sharma S, Chatterjee S. Microplastic pollution, a threat to marine ecosystem and human health: a short review. Environ Sci Pollut Res. 2017:24:21530-47.

3. Jendrossek D. Polyhydroxyalkanoate granules are complex subcellular organelles (carbonosomes). J Bacteriol. 2009;191 (10):3195-202.

4. Han J, Wu LP, Hou J, Zhao D, Xiang H. Biosynthesis, characterization, and hemostasis potential of tailor-made poly(3-hydroxybutyrate-co3-hydroxyvalerate) produced by Haloferax mediterranei. Biomacromol. 2015;16:578-88.

5. Han J, Wu LP, Liu XB, Hou J, Zhao LL, Chen JY, Zhao DH, Xiang H. Biodegradation and biocompatibility of haloarchaea-produced poly (3-hydroxybutyrate-co-3-hydroxyvalerate) copolymers. Biomaterials. 2017;139:172-86.

6. Lee Y, Cho IJ, Choi SY, Lee SY. Systems metabolic engineering strategies for non-natural microbial polyester production. Biotechnol J. 2019:14:1800426.

7. Albuquerque PB, Malafaia CB. Perspectives on the production, structural characteristics and potential applications of bioplastics derived from polyhydroxyalkanoates. Int J Biol Macromol. 2018;107:615-25.

8. Yin J, Chen JC, Wu Q, Chen GQ. Halophiles, coming stars for industrial biotechnology. Biotechnol Adv. 2015;33:1433-42.

9. Edbeib MF, Wahab RA, Huyop F. Halophiles: biology, adaptation, and their role in decontamination of hypersaline environments. World J Microbiol Biotechnol. 2016;32:135.

10. Bolhuis A, Kwan D, Thomas JR. Halophilic adaptations of proteins. In: Siddiqui KS, Thomas T, editors. Protein adaptation in extremophiles. New York: Nova Science Publishers; 2008. p. 71-104.

11. Youssef NH, Savage-Ashlock KN, McCully AL, Luedtke B, Shaw El, Hoff WD, Elshahed MS. Trehalose/2-sulfotrehalose biosynthesis and glycinebetaine uptake are widely spread mechanisms for osmoadaptation in the Halobacteriales. ISME J. 2014:8:636-49.

12. Kolp S, Pietsch M, Galinski EA, Gütschow M. Compatible solutes as protectants for zymogens against proteolysis. Biochim Biophys Acta Proteins Proteom. 2006;1764:1234-42.

13. Delgado-García M, Valdivia-Urdiales B, Aguilar-González CN, ContrerasEsquivel JC, Rodríguez-Herrera R. Halophilic hydrolases as a new tool for the biotechnological industries. J Sci Food Agric. 2012;92:2575-80.

14. Zuo Z, Xue Q, Zhou J, Zhao DH, Han J, Xiang H. Engineering Haloferax mediterranei as an efficient platform for high level production of lycopene. Front Microbiol. 2018;9:2893.

15. Kourmentza C, Plácido J, Venetsaneas N, Burniol-Figols A, Varrone C, Gavala HN, Reis MA. Recent advances and challenges towards sustainable polyhydroxyalkanoate (PHA) production. Bioengineering. 2017:4:55.

16. Quillaguamán J, Guzmán H, Van-Thuoc D, Hatti-Kaul R. Synthesis and production of polyhydroxyalkanoates by halophiles: current potential and future prospects. Appl Microbiol Biotechnol. 2010;85:1687-96.

17. Obruca S, Sedlacek P, Koller M, Kucera D, Pernicova I. Involvement of polyhydroxyalkanoates in stress resistance of microbial cells: biotechnological consequences and applications. Biotechnol Adv. 2018;36:856-70.

18. Liu C, Baffoe DK, Zhang M, Li Y, Zhan Y, Zhang G. Halophile, an essential platform for bioproduction. J Microbiol Methods. 2019:166:105704.

19. Huang Z, Wang $Y$, Jiang $L, X u B$, Wang $Y$, Zhao H, Zhou W. Mechanism and performance of a self-flocculating marine bacterium in saline wastewater treatment. Chem Eng J. 2018;334:732-40.

20. Jendrossek D, Pfeiffer D. New insights in the formation of polyhydroxyalkanoate granules (carbonosomes) and novel functions of poly (3-hydroxybutyrate). Environ Microbiol. 2014;16:2357-73.

21. Koller M. Polyhydroxyalkanoate Biosynthesis at the edge of water activitiy-Haloarchaea as biopolyester factories. Bioengineering. 2019;6:34.

22. Meng DC, Shen R, Yao H, Chen JC, Wu Q, Chen GQ. Engineering the diversity of polyesters. Curr Opin Biotechnol. 2014;29:24-33.

23. Koller M, Hesse P, Bona R, Kutschera C, Atlić A, Braunegg G. Biosynthesis of high quality polyhydroxyalkanoate co-and terpolyesters for potential medical application by the archaeon Haloferax mediterranei. Macromol Symp. 2007;253:33-9.

24. Ren Y, Ling C, Hajnal I, Wu Q, Chen GQ. Construction of Halomonas bluephagenesis capable of high cell density growth for efficient PHA production. Appl Microbiol Biotechnol. 2018;102:4499-510. 
25. Chen Y, Chen XY, Du HT, Zhang X, Ma YM, Chen JC, Ye JW, Jiang XR, Chen GQ. Chromosome engineering of the TCA cycle in Halomonas bluephagenesis for production of copolymers of 3-hydroxybutyrate and 3-hydroxyvalerate (PHBV). Metab Eng. 2019;54:69-82.

26. Ye J, Hu D, Yin J, Huang W, Xiang R, Zhang L, Wang X, Han J, Chen GQ. Stimulus response-based fine-tuning of polyhydroxyalkanoate pathway in Halomonas. Metab Eng. 2020:57:85-95.

27. Kirk RG, Ginzburg M. Ultrastructure of two species of halobacterium. J Ultrastruct Res. 1972:41:80-94

28. Fernandez-Castillo R, Rodriguez-Valera F, Gonzalez-Ramos J, Ruiz-Berraquero F. Accumulation of poly ( $\beta$-hydroxybutyrate) by halobacteria. Appl Environ Microbiol. 1986;51:214-6.

29. Altekar W, Rajagopalan R. Ribulose bisphosphate carboxylase activity in halophilic Archaebacteria. Arch Microbiol. 1990;153:169-74.

30. Nicolaus B, Lama L, Esposito E, Manca MC, Improta R, Bellitti MR, Duckworth AW, Grant WD, Gambacorta A. Haloarcula spp able to biosynthesize exo-and endopolymers. J Ind Microbiol Biotechnol. 1999;23:489-96.

31. Hezayen FF, Rehm BH, Eberhardt R, Steinbüchel A. Polymer production by two newly isolated extremely halophilic archaea: application of a novel corrosion-resistant bioreactor. Appl Microbiol Biotechnol. 2000;54:319-25

32. Hezayen FF, Gutiérrez MC, Steinbüchel A, Tindall BJ, Rehm BH. Halopiger aswanensis sp. nov., a polymer-producing and extremely halophilic archaeon isolated from hypersaline soil. Int J Syst Evol Microbiol. 2010;60:633-7.

33. Burns DG, Janssen PH, Itoh T, Kamekura M, Li Z, Jensen G, RodriguezValera F, Bolhuis H, Dyall-Smith ML. Haloquadratum walsbyi gen. nov., sp. nov., the square haloarchaeon of Walsby, isolated from saltern crystallizers in Australia and Spain. Int J Syst Evol Microbiol. 2007;57:387-92.

34. Hezayen FF, Tindall BJ, Steinbüchel A, Rehm BH. Characterization of a novel halophilic archaeon, Halobiforma haloterrestris gen. nov., sp. nov., and transfer of Natronobacterium nitratireducens to Halobiforma nitratireducens comb. nov. Int J Syst Evol Microbiol. 2002;52:2271-80.

35. Han J, Hou J, Liu H, Cai S, Feng B, Zhou J, Xiang H. Wide distribution among halophilic archaea of a novel polyhydroxyalkanoate synthase subtype with homology to bacterial type III synthases. Appl Environ Microbiol. 2010;76:7811-9.

36. Legat A, Gruber C, Zangger K, Wanner G, Stan-Lotter H. Identification of polyhydroxyalkanoates in Halococcus and other haloarchaeal species. Appl Microbiol Biotechnol. 2010;87:1119-27.

37. Romano I, Poli A, Finore I, Huertas FJ, Gambacorta A, Pelliccione S, Nicolaus G, Lama L, Nicolaus B. Haloterrigena hispanica sp. nov., an extremely halophilic archaeon from Fuente de Piedra, southern Spain. Int I Syst Evol Microbiol. 2007;57(7):1499-503.

38. Williams TJ, Liao Y, Ye J, Kuchel RP, Poljak A, Raftery MJ, Cavicchioli R. Cold adaptation of the Antarctic haloarchaea Halohasta litchfieldiae and Halorubrum lacusprofundi. Environ Microbiol. 2017;19:2210-27.

39. Don TM, Chen CW, Chan TH. Preparation and characterization of poly (hydroxyalkanoate) from the fermentation of Haloferax mediterranei. J Biomater Sci Polym Ed. 2006;17:1425-38,

40. Koller M, Hesse P, Bona R, Kutschera C, Atlić A, Braunegg G. Potential of various archae-and eubacterial strains as industrial polyhydroxyalkanoate producers from whey. Macromol Biosci. 2007;7:218-26.

41. Lu Q, Han J, Zhou L, Zhou J, Xiang H. Genetic and biochemical characterization of the poly (3-hydroxybutyrate-co-3-hydroxyvalerate) synthase in Haloferax mediterranei. J Bacteriol. 2008;190:4173-80.

42. Salgaonkar BB, Bragança JM. Biosynthesis of poly (3-hydroxybutyrate-co-3-hydroxyvalerate) by Halogeometricum borinquense strain E3. Int J Biol Macromol. 2015;78:339-46.

43. Salgaonkar B, Bragança J. Utilization of sugarcane bagasse by Halogeometricum borinquense strain $\mathrm{E} 3$ for biosynthesis of poly (3-hydroxybutyrate-co-3-hydroxyvalerate). Bioengineering. 2017;4:50.

44. Danis O, Ogan A, Tatlican P, Attar A, Cakmakci E, Mertoglu B, Birbir M. Preparation of poly(3-hydroxybutyrate-co-hydroxyvalerate) films from halophilic archaea and their potential use in drug delivery. Extremophiles. 2015;19:515-24.

45. Mahansaria R, Dhara A, Saha A, Haldar S, Mukherjee J. Production enhancement and characterization of the polyhydroxyalkanoate produced by Natrinema ajinwuensis (as synonym) $\equiv$ Natrinema altunense strain RM-G10. Int J Biol Macromol. 2018;107:1480-90.
46. Zhao YX, Rao ZM, Xue YF, Gong P, Ji YZ, Ma YH. Poly (3-hydroxybutyrate-co-3-hydroxyvalerate) production by Haloarchaeon Halogranum amylolyticum. Appl Microbiol Biotechnol. 2015;99:7639-49.

47. Quillaguaman J, Delgado O, Mattiasson B, Hatti-Kaul R. Poly( $\beta$ hydroxybutyrate) production by a moderate halophile, Halomonas boliviensis LC1. Enzyme Microb Technol. 2006;38:148-54.

48. Quillaguaman J, Hashim S, Bento F, Mattiasson B, Hatti-Kaul R. Poly( $\beta-$ hydroxybutyrate) production by a moderate halophile, Halomonas boliviensis LC1 using starch hydrolysate as substrate. J Appl Microbiol. 2005;99:151-7.

49. Van-Thuoc D, Quillaguaman J, Mamo G, Mattiasson B. Utilization of agricultural residues for poly(3-hydroxybutyrate) production by Halomonas boliviensis LC1. J Appl Microbiol. 2008;104:420-8.

50. Kawata Y, Aiba SI. Poly (3-hydroxybutyrate) production by isolated Halomonas sp. KM-1 using waste glycerol. Biosci Biotechnol Biochem. 2010;74:175.

51. Tan D, Xue YS, Aibaidula G, Chen GQ. Unsterile and continuous production of polyhydroxybutyrate by Halomonas TD01. Bioresour Technol. 2011;102:8130-6.

52. Cai L, Tan D, Aibaidula G, Dong XR, Chen JC, Tian WD, Chen GQ. Comparative genomics study of polyhydroxyalkanoates (PHA) and ectoine relevant genes from Halomonas sp. TD01 revealed extensive horizontal gene transfer events and co-evolutionary relationships. Microb Cell Fact. 2011;10:88.

53. Biswas A, Patra A, Paul A. Production of poly-3-hydroxyalkanoic acids by a moderately halophilic bacterium, Halomonas marina HMA 103 isolated from solar saltern of Orissa, India. Acta Microbiol Immunol Hung. 2009;56:125-43.

54. Simon-Colin C, Raguénès G, Cozien J, Guezennec JG. Halomonas profundus sp. nov., a new PHA-producing bacterium isolated from a deepsea hydrothermal vent shrimp. J Appl Microbiol. 2008;104:1425-32.

55. Hong JW, Song HS, Moon YM, Hong YG, Bhatia SK, Jung HR, Choi TR, Yang SY, Park HY, Choi YK, Yang YH. Polyhydroxybutyrate production in halophilic marine bacteria Vibrio proteolyticus isolated from the Korean peninsula. Bioprocess Biosyst Eng. 2019;42:603-10.

56. Kulkarni SO, Kanekar PP, Nilegaonkar SS, Sarnaik SS, Jog JP. Production and characterization of a biodegradable poly(hydroxybutyrate-cohydroxyvalerate) (PHB-co-PHV) copolymer by moderately haloalkalitolerant Halomonas campisalis MCM B-1027 isolated from Lonar Lake, India. Bioresour Technol. 2010;101:9765-71.

57. Van-Thuoc D, Huu-Phong T, Minh-Khuong D, Hatti-Kaul R. Poly(3hydroxybutyrate-co-3-hydroxyvalerate) production by a moderate halophile Yangia sp. ND199 using glycerol as a carbon source. Appl Biochem Biotechnol. 2015;175:3120-32.

58. Chen GQ. Industrial production of PHA. In: Chen GQ, editor. Plastics from bacteria. Microbiology monographs. Heidelberg: Springer; 2010. p. 121-32.

59. Schmidt M, lenczak JL, Quines LK, Zanfonato K, Schmidell W, de Aragão GM. Poly(3-hydroxybutyrate-co-3-hydroxyvalerate) production in a system with external cell recycle and limited nitrogen feeding during the production phase. Biochem Eng J. 2016;112:130-5.

60. dos Santos JF, Canettieri EV, Souza SM, Rodrigues RC, Martínez EA. Treatment of sugarcane vinasse from cachaça production for the obtainment of Candida utilis CCT 3469 biomass. Biochem Eng J. 2019;148:131-7.

61. Bhattacharyya A, Pramanik A, Maji SK, Haldar S, Mukhopadhyay UK, Mukherjee J. Utilization of vinasse for production of poly3-(hydroxybutyrate-co-hydroxyvalerate) by Haloferax mediterranei. AMB Express. 2012;2:34.

62. Alsafadi D, Al-Mashaqbeh O. A one-stage cultivation process for the production of poly-3-(hydroxybutyrate-co-hydroxyvalerate) from olive mill wastewater by Haloferax mediterranei. New Biotechnol. 2017:34:47-53.

63. Hou J, Han J, Cai L, Zhou J, Lü Y, Jin C, Liu J, Xiang H. Characterization of genes for chitin catabolism in Haloferax mediterranei. Appl Microbiol Biotechnol. 2014;98:1185-94.

64. Pais J, Serafim LS, Freitas F, Reis MA. Conversion of cheese whey into poly(3-hydroxybutyrate-co-3-hydroxyvalerate) by Haloferax mediterranei. New Biotechnol. 2016;33:224-30.

65. Bhattacharyya A, Saha J, Haldar S, Bhowmic A, Mukhopadhyay UK, Mukherjee J. Production of 
poly-3-(hydroxybutyrate-co-hydroxyvalerate) by Haloferax mediterranei using rice-based ethanol stillage with simultaneous recovery and reuse of medium salts. Extremophiles. 2014;18:463-70.

66. Bhattacharyya A, Jana K, Haldar S, Bhowmic A, Mukhopadhyay UK, De $\mathrm{S}$, Mukherjee J. Integration of poly-3-(hydroxybutyrate-co-hydroxyvalerate) production by Haloferax mediterranei through utilization of stillage from rice-based ethanol manufacture in India and its techno-economic analysis. World J Microbiol Biotechnol. 2015;31:717-27.

67. García IL, Dorado MP, López JA, Villarb MA, Yanniotis S, Koutinas A. Design and techno-economic evaluation of microbial biopolymer production from food industry wastes and agricultural crops. In: International Congress on Engineering and Food. 2012.

68. Hermann-Krauss C, Koller M, Muhr A, Fasl H, Stelzer F, Braunegg $\mathrm{G}$. Archaeal production of polyhydroxyalkanoate (PHA) co-and terpolyesters from biodiesel industry-derived by-products. Archaea. 2013;2013:129268.

69. Pramanik A, Mitra A, Arumugam M, Bhattacharyya A, Sadhukhan S, Ray A, Haldar S, Mukhopadhyay UK, Mukherjee J. Utilization of vinasse for the production of polyhydroxybutyrate by Haloarcula marismortui. Folia Microbiol. 2012:57:71-9.

70. Nielsen MM, Bruhn A, Rasmussen MB, Olesen B, Larsen MM, Møller HB. Cultivation of Ulva lactuca with manure for simultaneous bioremediation and biomass production. J Appl Phycol. 2012;24:449-58.

71. Ghosh S, Gnaim R, Greiserman S, Fadeev L, Gozin M, Golberg A. Macroalgal biomass subcritical hydrolysates for the production of polyhydroxyalkanoate (PHA) by Haloferax mediterranei. Bioresour Technol. 2019;271:166-73.

72. Koller M. Recycling of waste streams of the biotechnological poly(hydroxyalkanoate) production by Haloferax mediterranei on whey. Int J Polym Sci. 2015;2015:1-8.

73. Kucera D, Pernicová I, Kovalcik A, Koller M, Mullerova L, Sedlacek P, Mravec F, Nebesarova J, Kalina M, Marova I, Krzyzanek V. Characterization of the promising poly (3-hydroxybutyrate) producing halophilic bacterium Halomonas halophila. Bioresour Technol. 2018;256:552-6.

74. García-Torreiro M, Lu-Chau T, Steinbuchel A, Lema J. Waste to bioplastic conversion by the moderate halophilic bacterium Halomonas boliviensis. Chem Eng Trans. 2016;49:163-8.

75. Sawant SS, Salunke BK, Kim BS. Degradation of corn stover by fungal cellulase cocktail for production of polyhydroxyalkanoates by moderate halophile Paracoccus sp. LL1. Bioresour Technol. 2015;194:247-55.

76. Pandey VC, Singh K, Singh JS, Kumar A, Singh B, Singh RP. Jatropha curcas: a potential biofuel plant for sustainable environmental development. Renew Sustain Energy Rev. 2012;16:2870-83.

77. Shrivastav A, Mishra SK, Shethia B, Pancha I, Jain D, Mishra S. Isolation of promising bacterial strains from soil and marine environment for polyhydroxyalkanoates (PHAs) production utilizing Jatropha biodiesel byproduct. Int J Biol Macromol. 2010;47:283-7.

78. Bera A, Dubey S, Bhayani K, Mondal D, Mishra S, Ghosh PK. Microbial synthesis of polyhydroxyalkanoate using seaweed-derived crude levulinic acid as co-nutrient. J Biol Macromol. 2015;72:487-94.

79. Cui YW, Zhang HY, Ji SY, Wang ZW. Kinetic analysis of the temperature effect on polyhydroxyalkanoate production by Haloferax mediterranei in synthetic molasses wastewater. J Polym Environ. 2017;25:277-85.

80. Lillo JG, Rodriguez-Valera F. Effects of culture conditions on poly( $\beta$ hydroxybutyric acid) production by Haloferax mediterranei. Appl Environ Microbiol. 1990;56:2517-21.

81. Ferre-Guell A, Winterburn J. Production of the copolymer poly(3hydroxybutyrate-co-3-hydroxyvalerate) with varied composition using different nitrogen sources with Haloferax mediterranei. Extremophiles. 2017:21:1037-47.

82. Cui YW, Shi YP, Gong XY. Effects of $C / N$ in the substrate on the simultaneous production of polyhydroxyalkanoates and extracellular polymeric substances by Haloferax mediterranei via kinetic model analysis. RSC Adv. 2017;7:18953-61.

83. Wen Q, Ji Y, Hao Y, Huang L, Chen Z, Sposob M. Effect of sodium chloride on polyhydroxyalkanoate production from food waste fermentation leachate under different organic loading rate. Bioresour Technol. 2018:267:133-40

84. Cui YW, Gong XY, Shi YP, Wang ZD. Salinity effect on production of PHA and EPS by Haloferax mediterranei. RSC Adv. 2017;7:53587-95.
85. Chen CW, Don TM, Yen HF. Enzymatic extruded starch as a carbon source for the production of poly(3-hydroxybutyrate-co-3-hydroxyvalerate) by Haloferax mediterranei. Process Biochem. 2006;41:2289-96.

86. Huang TY, Duan KJ, Huang SY, Chen CW. Production of polyhydroxyalkanoates from inexpensive extruded rice bran and starch by Haloferax mediterranei. J Ind Microbiol Biotechnol. 2006;33:701-6.

87. Stanley A, Kumar HP, Mutturi S, Vijayendra SN. Fed-batch strategies for production of PHA using a native isolate of Halomonas venusta KT832796 strain. Appl Biochem Biotechnol. 2018;184:935-52.

88. Sarma MV, Gautam A, Kumar L, Saharan K, Kapoor A, Shrivastava N, Sahai V, Bisaria VS. Bioprocess strategies for mass multiplication of and metabolite synthesis by plant growth promoting pseudomonads for agronomical applications. Process Biochem. 2013:48:1418-24.

89. Quillaguamán J, Muñoz M, Mattiasson B, Hatti-Kaul R. Optimizing conditions for poly( $($-hydroxybutyrate) production by Halomonas boliviensis LC1 in batch culture with sucrose as carbon source. Appl Biochem Biotechnol. 2007;74:981.

90. Quillaguamán J, Doan-Van T, Guzmán H, Guzmán D, Martín J, Everest A, Hatti-Kaul R. Poly(3-hydroxybutyrate) production by Halomonas boliviensis in fed-batch culture. Appl Biochem Biotechnol. 2008;78:227-32

91. Guzmán H, Van-Thuoc D, Martín J, Hatti-Kaul R, Quillaguamán J. A process for the production of ectoine and poly(3-hydroxybutyrate) by Halomonas boliviensis. Appl Biochem Biotechnol. 2009;84:1069-77.

92. García-Torreiro M, López-Abelairas M, Lu-Chau TA, Lema JM. Production of poly(3-hydroxybutyrate) by simultaneous saccharification and fermentation of cereal mash using Halomonas boliviensis. Biochem Eng J. 2016;114:140-6.

93. Rivera-Terceros P, Tito-Claros E, Torrico S, Carballo S, Van-Thuoc D, Quillaguamán J. Production of poly(3-hydroxybutyrate) by Halomonas boliviensis in an air-lift reactor. J Biol Res. 2015:22:8.

94. Kshirsagar PR, Suttar R, Nilegaonkar SS, Pradhan S, Kanekar PP. Scale up production of polyhydroxyalkanoate (PHA) at different aeration, agitation and controlled dissolved oxygen levels in fermenter using Halomonas campisalis MCM B-1027. J Biochem Technol. 2013;4:512-7.

95. Yue H, Ling C, Yang T, Chen X, Chen Y, Deng H, Wu Q, Chen J, Chen GQ. A seawater-based open and continuous process for polyhydroxyalkanoates production by recombinant Halomonas campaniensis LS21 grown in mixed substrates. Biotechnol Biofuels. 2014;7:108.

96. Koller M, Rodríguez-Contreras A. Techniques for tracing PHA-producing organisms and for qualitative and quantitative analysis of intra-and extracellular PHA. Eng Life Sci. 2015;15:558-81.

97. García-Torreiro M, López-Abelairas M, Lu-Chau TA, Lema JM. Application of flow cytometry for monitoring the production of poly(3-hydroxybutyrate) by Halomonas boliviensis. Biotechnol Prog. 2017;33:276-84.

98. Fu XZ, Tan D, Aibaidula G, Wu Q, Chen JC, Chen GQ. Development of Halomonas TD01 as a host for open production of chemicals. Metab Eng. 2014;23:78-91.

99. Han J, Hou J, Zhang F, Ai G, Li M, Cai S, Liu H, Wang L, Wang Z, Zhang S, Cai L. Multiple propionyl coenzyme A-supplying pathways for production of the bioplastic poly(3-hydroxybutyrate-co-3-hydroxyvalerate) in Haloferax mediterranei. Appl Environ Microbiol. 2013;79:2922-31.

100. Liu G, Cai S, Hou J, Zhao D, Han J, Zhou J, Xiang H. Enoyl-CoA hydratase mediates polyhydroxyalkanoate mobilization in Haloferax mediterranei. Sci Rep. 2016;6:24015.

101. Ilham M, Nakanomori S, Kihara T, Hokamura A, Matsusaki H, Tsuge T, Mizuno K. Characterization of polyhydroxyalkanoate synthases from Halomonas sp. O-1 and Halomonas elongata DSM2581: Site-directed mutagenesis and recombinant expression. Polym Degrad Stab. 2014;109:416-23.

102. Elain A, Le Fellic M, Corre YM, Le Grand A, Le Tilly V, Audic JL, Bruzaud S. Rapid and qualitative fluorescence-based method for the assessment of PHA production in marine bacteria during batch culture. World J Microbiol Biotechnol. 2015:31:1555-63.

103. Thomas T, Elain A, Bazire A, Bruzaud S. Complete genome sequence of the halophilic PHA-producing bacterium Halomonas sp. SF2003: insights into its biotechnological potential. World J Microbiol Biotechnol. 2019;35:50.

104. Han J, Lu Q, Zhou L, Zhou J, Xiang H. Molecular characterization of the phaEC $C_{\mathrm{Hm}}$ genes, required for biosynthesis of poly(3-hydroxybutyrate) in 
the extremely halophilic archaeon Haloarcula marismortui. Appl Environ Microbiol. 2007;73:6058-65.

105. Han J, Li M, Hou J, Wu L, Zhou J, Xiang H. Comparison of four phaC genes from Haloferax mediterranei and their function in different PHBV copolymer biosyntheses in Haloarcula hispanica. Saline Syst. 2010;6:9.

106. Williamson A, De Santi C, Altermark B, Karlsen C, Hjerde E. Complete genome sequence of Halomonas sp. R5-57. Stand Genomic Sci. 2016;11:62.

107. Lau NS, Sam KK, Amirul AA. Genome features of moderately halophilic polyhydroxyalkanoate-producing Yangia sp. CCB-MM3. Stand Genomic Sci. 2017;12:12.

108. Martínez-Gutiérrez CA, Latisnere-Barragán H, García-Maldonado JQ, López-Cortés A. Screening of polyhydroxyalkanoate-producing bacteria and PhaC-encoding genes in two hypersaline microbial mats from Guerrero Negro, Baja California Sur, Mexico. PeerJ. 2018;6:e4780.

109. Hou J, Feng B, Han J, Liu H, Zhao D, Zhou J, Xiang H. Haloarchaealtype $\beta$-ketothiolases involved in poly(3-hydroxybutyrate-co3-hydroxyvalerate) synthesis in Haloferax mediterranei. Appl Environ Microbiol. 2013;79:5104-11.

110. Tao W, Lv L, Chen GQ. Engineering Halomonas species TD01 for enhanced polyhydroxyalkanoates synthesis via CRISPRi. Microb Cell Fact. 2017;16:48.

111. Tan D, Wu Q, Chen JC, Chen GQ. Engineering Halomonas TD01 for the low-cost production of polyhydroxyalkanoates. Metab Eng. 2014;26:34-47.

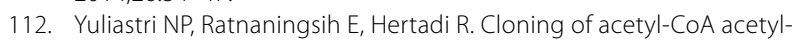
transferase gene from Halomonas elongata BK-AG18 and in silico analysis of its gene product. Indones J Biotechnol. 2017;22:39-42.

113. Feng B, Cai S, Han J, Liu H, Zhou J, Xiang H. Identification of the phaB genes and analysis of the PHBV precursor supplying pathway in Haloferax mediterranei. Wei sheng wu xue bao=Acta Microbiologica Sinica. 2010;50:1305-12.

114. Han J, Lu Q, Zhou L, Liu H, Xiang H. Identification of the polyhydroxyalkanoate (PHA)-specific acetoacetyl coenzyme A reductase among multiple FabG paralogs in Haloarcula hispanica and reconstruction of the PHA biosynthetic pathway in Haloferax volcanii. Appl Environ Microbiol. 2009;75:6168-75.

115. Ling C, Qiao GQ, Shuai BW, Olavarria K, Yin J, Xiang RJ, Song KN, Shen YH, Guo Y, Chen GQ. Engineering NADH/NAD+ ratio in Halomonas bluephagenesis for enhanced production of polyhydroxyalkanoates (PHA). Metab Eng. 2018:49:275-86.

116. Shen R, Ning ZY, Lan YX, Chen JC, Chen GQ. Manipulation of polyhydroxyalkanoate granular sizes in Halomonas bluephagenesis. Metab Eng. 2019;54:117-26.

117. Cai S, Cai L, Liu H, Liu X, Han J, Zhou J, Xiang H. Identification of the haloarchaeal phasin (PhaP) that functions in polyhydroxyalkanoate accumulation and granule formation in Haloferax mediterranei. Appl Environ Microbiol. 2012;78:1946-52.

118. Cai S, Cai L, Zhao D, Liu G, Han J, Zhou J, Xiang H. A novel DNA binding protein, PhaR, plays a central role in the regulation of polyhydroxyalkanoate accumulation and granule formation in the haloarchaeon Haloferax mediterranei. Appl Environ Microbiol. 2015:81:373-85.

119. Liu J, Wang Q, Jiang X, Yang H, Zhao D, Han J, Luo Y, Xiang H. Systematic analysis of lysine acetylation in the halophilic archaeon Haloferax mediterranei. J Proteome Res. 2017;16:3229-41.

120. Jiang X, Wang Q, Liu G, Zhao D, Liu J, Xiang H. Acetylation regulates the function of PhaE in Haloferax mediterranei. Acta Microbiologica Sinica. 2017;57:1665-75.

121. Liu G, Hou J, Cai S, Zhao D, Cai L, Han J, Zhou J, Xiang H. A patatin-like protein associated with the polyhydroxyalkanoate (PHA) granules of Haloferax mediterranei acts as an efficient depolymerase in the degradation of native PHA. Appl Environ Microbiol. 2015;81:3029-38.

122. Yin J, Wang H, Fu XZ, Gao X, Wu Q, Chen GQ. Effects of chromosomal gene copy number and locations on polyhydroxyalkanoate synthesis by Escherichia coli and Halomonas sp. Appl Microbiol Biotechnol. 2015;99:5523-34

123. Lemechko P, Le Fellic M, Bruzaud S. Production of poly(3-hydroxybutyrate-co-3-hydroxyvalerate) using agro-industrial effluents with tunable proportion of 3-hydroxyvalerate monomer units. Int J Biol Macromol. 2019:128:429-34.
124. Ye J, Huang W, Wang D, Chen F, Yin J, Li T, Zhang H, Chen GQ. Pilot scale-up of poly(3-hydroxybutyrate-co-4-hydroxybutyrate) production by Halomonas bluephagenesis via cell growth adapted optimization process. Biotechnol J. 2018;13:1800074.

125. Li ZJ, Shi ZY, Jian J, Guo YY, Wu Q, Chen GQ. Production of poly(3hydroxybutyrate-co-4-hydroxybutyrate) from unrelated carbon sources by metabolically engineered Escherichia coli. Metab Eng. 2010;12:352-9.

126. Chen X, Yin J, Ye J, Zhang H, Che X, Ma Y, Li M, Wu LP, Chen GQ. Engineering Halomonas bluephagenesis TD01 for non-sterile production of poly(3-hydroxybutyrate-co-4-hydroxybutyrate). Bioresour Technol. 2017:244:534-41

127. Shen R, Yin J, Ye JW, Xiang RJ, Ning ZY, Huang WZ, Chen GQ. Promoter engineering for enhanced $\mathrm{P}$ (3HB-co-4HB) production by Halomonas bluephagenesis. ACS Synth Biol. 2018;7:1897-906.

128. Ye J, Hu D, Che X, Jiang X, Li T, Chen J, Zhang HM, Chen GQ. Engineering of Halomonas bluephagenesis for low cost production of poly(3hydroxybutyrate-co-4-hydroxybutyrate) from glucose. Metab Eng. 2018;47:143-52.

129. Jan J, Martinez I, Wang Y, Bennett GN, San KY. Metabolic engineering and transhydrogenase effects on NADPH availability in Escherichia coli. Biotechnol Prog. 2013;29:1124-30.

130. Lee HC, Kim JS, Jang W, Kim SY. High NADPH/NADP + ratio improves thymidine production by a metabolically engineered Escherichia coli strain. J Biotechnol. 2010;149:24-32.

131. Sánchez AM, Andrews J, Hussein I, Bennett GN, San KY. Effect of overexpression of a soluble pyridine nucleotide transhydrogenase (UdhA) on the production of poly(3-hydroxybutyrate) in Escherichia coli. Biotechnol Prog. 2006;22:420-5.

132. Romero S, Merino E, Bolívar F, Gosset G, Martinez A. Metabolic engineering of Bacillus subtilis for ethanol production: lactate dehydrogenase plays a key role in fermentative metabolism. Appl Environ Microbiol. 2007;73:5190-8.

133. Yin J, Fu XZ, Wu Q, Chen JC, Chen GQ. Development of an enhanced chromosomal expression system based on porin synthesis operon for halophile Halomonas sp. Appl Microbiol Biotechnol. 2014;98:8987-97.

134. Li T, Li T, Ji W, Wang Q, Zhang H, Chen GQ, Lou C, Ouyang Q. Engineering of core promoter regions enables the construction of constitutive and inducible promoters in Halomonas sp. Biotechnol J. 2016;11:219-27.

135. Zhao H, Zhang HM, Chen X, Li T, Wu Q, Ouyang Q, Chen GQ Novel T7-like expression systems used for Halomonas. Metab Eng. 2017;39:128-40.

136. Stark BC, Pagilla KR, Dikshit KL. Recent applications of Vitreoscilla hemoglobin technology in bioproduct synthesis and bioremediation. Appl Microbiol Biotechnol. 2015;99:1627-36.

137. Ouyang P, Wang H, Hajnal I, Wu Q, Guo Y, Chen GQ. Increasing oxygen availability for improving poly(3-hydroxybutyrate) production by Halomonas. Metab Eng. 2018:45:20-31.

138. Jiang $X R$, Yao ZH, Chen GQ. Controlling cell volume for efficient PHB production by Halomonas. Metab Eng. 2017:44:30-7.

139. Ling C, Qiao GQ, Shuai BW, Song KN, Yao WX, Jiang XR, Chen GQ. Engineering self-flocculating Halomonas campaniensis for wastewaterless open and continuous fermentation. Biotechnol Bioeng. 2019;116:805-15

140. Zhao Y, Rao Z, Xue Y, Gong P, Ji Y, Ma Y. Biosynthesis, property comparison, and hemocompatibility of bacterial and haloarchaeal poly (3hydroxybutyrate-co-3-hydroxyvalerate). Sci Bull. 2015;60:1901-10.

141. Zhao D, Cai L, Wu J, Li M, Liu H, Han J, Zhou J, Xiang H. Improving polyhydroxyalkanoate production by knocking out the genes involved in exopolysaccharide biosynthesis in Haloferax mediterranei. Appl Microbiol Biotechnol. 2013;97(7):3027-36.

142. Chen J, Mitra R, Zhang S, Zuo Z, Lin L, Zhao D, Xiang H, Han J. Unusual phosphoenolpyruvate (PEP) synthetase-like protein crucial to enhancement of polyhydroxyalkanoate accumulation in Haloferax mediterranei revealed by dissection of PEP-pyruvate interconversion mechanism. Appl Environ Microbiol. 2019;85:e00984-19.

143. Ferre-Guell A, Winterburn J. Biosynthesis and characterization of polyhydroxyalkanoates with controlled composition and microstructure. Biomacromolecules. 2018;19(3):996-1005. 
144. Kawata Y, Kawasaki K, Shigeri Y. Draft genome sequence of Halomonas sp. strain KM-1, a moderately halophilic bacterium that produces the bioplastic poly(3-hydroxybutyrate). J Bacteriol. 2012;194:2738-9.

145. Cervantes-Uc JM, Catzin J, Vargas I, Herrera-Kao W, Moguel F, Ramirez E, Rincón-Arriaga S, Lizama-Uc G. Biosynthesis and characterization of polyhydroxyalkanoates produced by an extreme halophilic bacterium, Halomonas nitroreducens, isolated from hypersaline ponds. J Appl Microbiol. 2014;117:1056-65.

146. Bouchotroch S, Quesada E, del Moral A, Llamas I, Bejar V. Halomonas maura sp. nov., a novel moderately halophilic, exopolysaccharideproducing bacterium. Int J Syst Evol Microbiol. 2001;51:1625-32.
147. Martínez-Cánovas MJ, Quesada E, Llamas I, Bejar V. Halomonas ventosae sp. nov, a moderately halophilic, denitrifying, exopolysaccharide-producing bacterium. Int J Syst Evol Microbiol. 2004;54:733-7.

148. Mothes G, Schubert T, Harms H, Maskow T. Biotechnological coproduction of compatible solutes and polyhydroxyalkanoates using the genus Halomonas. Eng Life Sci. 2008;8:658-62.

\section{Publisher's Note}

Springer Nature remains neutral with regard to jurisdictional claims in published maps and institutional affiliations.
Ready to submit your research? Choose BMC and benefit from:

- fast, convenient online submission

- thorough peer review by experienced researchers in your field

- rapid publication on acceptance

- support for research data, including large and complex data types

- gold Open Access which fosters wider collaboration and increased citations

- maximum visibility for your research: over $100 \mathrm{M}$ website views per year

At BMC, research is always in progress.

Learn more biomedcentral.com/submissions 